\title{
LA CONSUMACIÓN DE LA \\ INDEPENDENCIA EN PRODUCCIONES ESCOLARES DE SECUNDARIA DEL SIGLO XXI EN MÉXICO
}

\author{
THE CONSUMMATION OF INDEPENDENCE \\ IN SECONDARY SCHOOL PRODUCTIONS OF \\ THE XXI CENTURY IN MEXICO
}

\author{
María Guadalupe Mendoza Ramírez \\ Universidad Pedagógica Nacional \\ mmendozaupntoluca@gmail.com \\ Rodolfo Huerta González \\ Universidad Pedagógica Nacional \\ rhuerta12@gmail.com \\ Rodolfo Cruz Bustos \\ Universidad Pedagógica Nacional \\ rcbustos@gmail.com
}

\begin{abstract}
The article discusses historical and pedagogical meanings in secondary school literature on the Consummation of the Independence of Mexico and the significance of the evaluation. We analyze activities in 13 third-grade notebooks on the History of Mexico from 2010 to 2016. The content of the 2006, 2011 and 2017 curricular framework was explored through ATLAS.ti software, and we addressed four axes: a) temporal sequencing of historical knowledge; b) chronology, periodization and representation in time lines; c) representation of space and historical facts on maps and images and d) content logic in graphic organizers and summaries.
\end{abstract}

Keywords: Teaching of History, Secondary education, school notebooks.

\section{Resumen}

El artículo discute significados históricos y pedagógicos en producciones escolares de secundaria sobre la Consumación de la Independencia de México y cuáles son los sentidos de la evaluación. Se analizan actividades en 13 cuadernos de Historia de México de tercer grado de 2010 a 2016. Se explora con ATLAS.ti el contenido del marco curricular de 2006, 2011 y 2017, y se atienden estos ejes: a) secuenciación temporal del conocimiento histórico; b) cronología, periodización y representación en líneas del tiempo; c) representación del espacio y hechos históricos en mapas e imágenes; d) lógica del contenido en los organizadores gráficos y resúmenes.

Palabras clave: Enseñanza de la Historia, Educación secundaria, cuadernos escolares. 


\section{Introducción}

En México, diversas investigaciones (Mirnada López y Reynoso Angulo, 2006; Salazar Sotelo, 2018) sostienen la hipótesis de que asistimos, desde el inicio del siglo XXI, a una drástica reducción del peso de la Historia en los currículos de educación básica. El argumento que se esgrime es que las reformas educativas provocaron cambios en los modelos de enseñanza: se priorizaron las habilidades para el uso de la tecnología y la enseñanza del inglés y, en contraste, se redujo la importancia de la Historia como disciplina, sobre todo en la escuela secundaria. A la par, se modificaron los programas, los libros de texto y el papel del docente como agente educativo. En este nuevo contexto educativo, marcado por la incorporación del modelo por competencias que tuvo sus cimientos en la reforma de secundaria de 2006, la Historia enseñada y el contenido temático, como el de la Independencia y su Consumación, han reducido su peso curricular, o bien han transmutado en su tratamiento pedagógico.

Otras investigaciones vislumbran una paradoja, pues identifican que, hasta la primera década de este siglo, la Independencia de México como contenido seguía teniendo relevancia social en la población en el rango de 12-18 años. En un estudio pionero acerca de la teoría y praxis de enseñanza de la historia, Andrea Sánchez Quintanar (2002) mostró los resultados de una encuesta y refirió que

la escuela es el lugar donde se adquiere el conocimiento histórico de manera principal (54\%), seguida de los libros (26.5\%). De entre seis hechos históricos de la historia de México, que se considerara el más importante [...] un tercio de los encuestados (36.6\%) piensa que México empieza a ser su patria "cuando conquista su independencia de España"' mostrando, a mi parecer, una idea que se forja con una de las variables de la enseñanza liberal decimonónica de la historia nacional: la que en aras de superar la pugna entre indigenistas

1 Las negritas son nuestras. e hispanistas, coloca el inicio de México como nación moderna -y por lo tanto como patria-, en la liberación política de la tutela extranjera (2002:113).

Para Sánchez Quintanar, estos resultados son una herencia decimonónica de los contenidos que la escuela ha forjado y mantenido en el imaginario social. Esto la lleva a concluir la importancia de la investigación en la enseñanza de la historia y la necesidad de que los historiadores enseñantes asuman el compromiso de enseñar a "pensar históricamente a quienes no son profesionales del trabajo histórico, en un mundo tan lleno de interrogantes, dudas y problemas como en el que vivimos hoy" (2002: 123).

Desde otra perspectiva teórica, anclada en los estudios de la enseñanza de la historia y la conformación de la ciudadanía, Julia Salazar Sotelo introduce al debate los resultados de una encuesta en una investigación de los jóvenes de tercero de secundaria de la Ciudad de México. En las respuestas de los jóvenes la autora identifica algunos elementos del nacionalismo. Sin embargo, apunta que en estos subyace una visión "esencialista” que no aporta significado a la conformación de las identidades juveniles en esta sociedad y sostiene que "la integración a una identidad cultural en México se ha desvanecido frente a las políticas de libre comercio que impone el neoliberalismo. Aun cuando ciertos rasgos de nacionalismo y de patriotismo siguen presentes discursivamente en la definición de la política educativa y cultural" (Salazar Sotelo, 2011: 2).

Desde estas premisas se cuestiona la función de la historia en la escuela secundaria, la cual se presenta alejada de la realidad de la educación de los jóvenes del siglo XXI. Los problemas de violencia, diferenciación, acceso a tecnología y deserción escolar, comunes a los jóvenes, obliga a los estudiosos a revisar las experiencias y las expectativas de futuro como ciudadanos de un mundo en transformación que genera profundas incertidumbres. En este nuevo contexto, es necesario revisar el papel de la historia escolar, y en particular, el tratamiento de los 
contenidos enseñados, con el objetivo de formular preguntas sobre las prácticas y el significado que tienen para los estudiantes de nuestro país (Salazar Sotelo, 2012).

El análisis de la historia como disciplina escolar en el siglo XXI representa, por ello, una posibilidad de asomarnos a la función educativa y pedagógica de la historia como producto de las reformas educativas que se dieron en 2006, 2011 y 2016, y repercutieron en la escuela secundaria, en el contexto de globalización y neoliberalismo. Esta investigación tiene la intención de analizar las siguientes interrogantes: ¿qué significados históricos y pedagógicos nos develan las producciones escolares de alumnos de secundaria en el siglo XXI sobre la Consumación de la Independencia de México?; ¿cuáles son los sentidos de la evaluación de este conocimiento escolar?

\section{La Historia enseñada y las producciones escolares en la investigación didáctica}

La investigación en el campo de la didáctica de la historia y las ciencias sociales en América Latina recupera de manera importante el concepto de la Historia enseñada para generar nuevas preguntas e hipótesis sobre la cultura en la escuela del siglo XXI. Los estudios empíricos centran su interés en documentar y analizar las prácticas y los modelos de enseñanza desarrollados en contextos tan disímbolos como Argentina, Chile, Colombia y Brasil. Asimismo, estudian el impacto que estas prácticas y modelos tienen en la formación del ciudadano.

La Historia enseñada es un constructo interdisciplinario que tiene entre sus autores centrales a Silvia Finocchio (2005), investigadora de la Facultad Latinoamericana de Ciencias Sociales (Flacso). La autora propone que para avanzar en la tarea de educar desde la historia es necesario revisar críticamente las prácticas de los dos actores centrales del proceso educativo: los maestros y los alumnos. Este abordaje teórico tiene como premisa que las prácticas, los saberes y los contenidos de la Historia enseñada no se reducen a las normas que han establecido los sistemas educativos y la prescripción del currículo (Finocchio y Romero, 2011).

El argumento de Finocchio se sustenta en dos sitios. Por una parte, en el concepto de código disciplinar acuñado por Raymundo Cuesta, sobre el origen de las disciplinas escolares. Cuesta define el concepto desde la conformación de los estados nacionales como

un arbitrario cultural creado históricamente en razón de la práctica de diversos agentes sociales, entre los que desempeñan un indudable protagonismo los profesores y los alumnos, las profesoras y las alumnas, que con su acción han creado y transformado a lo largo del tiempo una tradición social (Cuesta, 1997: 2).

Por otra parte, la segunda veta que alimenta este concepto es la aproximación a la cultura escolar, ya que para develar la permanencia o los cambios de los contenidos enseñados en las escuelas del siglo XXI "es necesario revisar la cultura escolar heredada de modo que los alumnos no sólo aprendan conceptos, como reglas y normas de la vida democrática, sino que vivan experiencias propias de una escuela democrática" (Finocchio, 2021: 42).

En relación con la comprensión de estas prácticas, es necesario investigar cómo los docentes leen el currículo social; cuáles son los modos de pensar y las formas en que los docentes resignifican los contenidos a enseñar y cómo con ello pueden recrear su papel de meros transmisores de conocimiento escolar en contextos diversos y momentos históricos específicos. La Historia enseñada, el saber escolar y las prácticas que la configuran históricamente son cambiantes y a su vez contienen elementos que permanecen y se ritualizan en las acciones cotidianas de los sujetos educativos (Cuesta, 1997).

Un segundo concepto que recuperamos en este trabajo es el de transposición didáctica, el cual es útil para dilucidar la Historia enseñada como objeto de estudio. Este concepto refiere a la necesaria transformación didáctica de los contenidos de enseñanza, 
en la que el maestro juega un papel central durante el proceso de enseñanza que le restituye su función en el acto de enseñar. La transposición didáctica implica el paso del saber sabio al saber enseñado (Chevallard, 1997: 16).

La Historia, como parte de las ciencias humanas, tiene un grado alto de abstracción, diversidad de interpretaciones, enfoques e información. A pesar de la necesaria transposición didáctica que le permite ser una asignatura escolar, sigue manteniendo un grado de abstracción considerable. Ello obliga a experimentar una segunda transposición. Ésta es realizada ahora por el docente, y se relaciona con su propia comprensión del tema específico del currículo oficial, con su dominio de los temas, con la importancia que le otorga a cada uno de ellos y con las características de cada uno de los grupos que atiende.

Por ello se vuelve necesario recuperar las transformaciones del código disciplinar a través de un doble ejercicio. Por un lado, desde la explicitación de un modo de mirar las prácticas escolares que ayude a captar sus transformaciones. Por otro lado, a partir de un conjunto de evidencias extraídas de un recorte y una fuente en particular: las actividades que se realizan en la asignatura de historia en el nivel secundaria. Para ello, se vuelve importante documentar las actividades y estrategias de enseñanza que el maestro de historia implementa en su práctica diaria, de manera que sea posible identificar "las invenciones producidas por los maestros" en los objetivos, contenido y forma en que se materializan las producciones escolares en un contexto específico.

Ahora bien, ¿cuál es la función pedagógica de los contenidos enseñados en la historia escolar y su relevancia social en el siglo XXI para los jóvenes y los profesores? Ante la necesidad de analizar las prácticas de enseñanza vinculadas con determinados contenidos históricos cuyo abordaje debe abandonar la visión positivista de la historia como un cúmulo de eventos el pasado, la Independencia nacional puede mirarse como un tema socialmente relevante para la formación de ciudadanos. Lo anterior es posible en tanto se permita a los jóvenes estudiantes debatir, actividad en la que es crucial la participación de los maestros:

Los contenidos como el de la independencia pueden ayudar a construir una perspectiva distinta que sea pertinente con la formación ciudadana de los estudiantes de secundaria pues el estudio de la Independencia Nacional efectivamente tiene implicancias para entender los conflictos de la sociedad actual, lo que precisamente contribuye a reflexionar sobre la relación pasado, presente y futuro, promoviendo que los estudiantes se sientan parte de los problemas en su contexto y se sitúen como parte de la solución (Villalón-Gálvez et al., 2020: 45).

Finalmente, las investigaciones didácticas han abordado como objeto de estudio los contenidos relevantes en la historiografía, los cuales son llevados a la escuela para identificar el tratamiento didáctico y su relevancia social en la historia latinoamericana reciente. Pregunta: ¿qué ha cambiado en el tratamiento de contenidos históricos y qué ha permitido renovarlos? Ello conduce a investigar cómo los docentes leen las aportaciones de las diversas tradiciones pedagógicas, cómo interpretan las normas curriculares y cómo traducen los contenidos escolares. En el marco de los procesos de reforma curricular y de la circulación de corrientes de innovación pedagógica, las prácticas docentes pueden ser concebidas como "experimentaciones" o "adaptaciones" de propuestas que recaen sobre los responsables de la enseñanza (González, 2017).

\section{La Historia de México en la reforma curricular en tres sexenios de gobierno en el siglo XXI, visos de las continuidades}

El imaginario de los movimientos sociales y políticos que marcaron la transformación de México como nación soberana e independiente durante los dos siglos pasados es 
visible desde distintas interpretaciones. El movimiento independentista, evento fundacional del Estado mexicano en el siglo XIX, representa un hito en la conciencia nacional. Como elemento de identidad del país, se ha puesto de manifiesto también el sesgo de las interpretaciones y las maneras de transmitirlas. Los movimientos insurgentes resultaron ser también fuente de diferencias y coincidencias entre intelectuales y grupos que activamente participaron en debates, marcados por ascensos y descensos en los mandos políticos de la esfera gubernamental y otros escenarios de decisión y poder.

En lo que respecta a las reformas educativas y la enseñanza de la Historia, el final del siglo $X X$ estuvo imbuido por debates que no concluyen en el presente siglo, sino que se profundizan. En lo correspondiente a la escuela secundaria, los años noventa en el país pusieron a prueba la obligatoriedad de este nivel educativo. En el marco curricular, la Historia fue una asignatura que se ubicó en el centro del debate. En primero y segundo grados de secundaria, los alumnos cursaban Historia Universal I y II, respectivamente, mientras que en tercer grado cursaban Historia de México que pretendiendo "suprimir la memorización de datos" se diluye la intención de analizar procesos, causalidad, tiempo histórico y otros (Quiroz, 1999: 102). Dicho intento cuestiona a la "historia [como] una absurda cronología, fastidiosa y desvinculada del sujeto que aprende" (Monterrosas Gil, 2000: 71), para arribar a una "que se acerque a los hechos de la vida cotidiana, que recupere la presencia de la gente común, la mentalidad colectiva de los pueblos" (Monterrosas Gil, 2000: 71). Con esa discusión en materia curricular se arriba al siglo XXI.

\section{La impronta de lo curricular en los albores del siglo XXI}

En los albores del siglo XXI, bajo la impronta de un nuevo gobierno en México, ${ }^{2}$ los cam-

2 Después de una transición tensa en el proceso electoral de 2000, con el triunfo del Partido Acción Nacional (PAN), un partido de derecha, se consiguió la alternancia en México. bios en educación anunciados en 2001 se concretaron discursivamente con un mal inicio para la Historia. En un texto publicado en noviembre de 2002, la Secretaría de Educación Pública (SEP) exculpaba a pie de página que sobre el Programa Nacional para la Actualización Permanente (PROnap), los profesores de educación secundaria han tenido acceso a ocho cursos de actualización para la enseñanza del Español, Matemáticas, Geografía, Biología, Química, Física, Lenguas extranjeras y Educación ambiental, pero "no se ofrecen cursos de Historia ni de Formación Cívica y Ética, pues a la fecha no existen sus correspondientes Libros para el Maestro" (SEP, 2002: 28). Era visible la preocupación con el nuevo modelo impulsado desde la oficialidad, encontrar en la práctica educativa ya "por fin la rendición de cuentas", en detrimento de la libertad pedagógica y la autonomía escolar como banderas de un movimiento magisterial emergente en esos principios de siglo.

Formalmente, hasta 2004 la SEP presentó una propuesta para la enseñanza de la Historia dentro de lo que se denominó la Reforma Integral para la Educación Básica (RIEB). En su argumentación, se le otorga a la Historia la función social de desarrollo de la conciencia histórica a partir de la noción de tiempo histórico. Aquella era una función importante en un país que iniciaba una transición política que ponía fin a un siglo de mantener un mismo entramado constitucional y andamiaje partidista bajo los impulsos de Partido Revolucionario Institucional (PRI).

La RIEB se pronunció explícitamente por un modelo por competencias, competencias para la vida, que "implica un saber hacer (habilidades) con saber (conocimiento), así como la valoración de las consecuencias del impacto de ese hacer (valores y actitudes)" (SEP, 2007a: 11). Dichos planteamientos se avizoraban en la oficialidad ya en décadas anteriores, pero no se habían concretado en ninguna reforma emprendida en México.

Dentro de los planteamientos pedagógicos y didácticos, la concepción establecía avanzar hacia "reorientar la práctica educa- 
tiva para que el desarrollo de capacidades y competencias cobrase primacía sobre la visión predominantemente memorística e informativa del aprendizaje" (SEP, 2007a: 17). Esto, en el caso de la Historia, fue un lastre sobre el que se hacía mención en años previos, pero sobre el que no se avanzaba en términos prácticos. En el mapa curricular la Historia aparece, en segundo y tercer grados, con 4 horas semanales (SEP, 2007b: 31). En dichos niveles se busca que los estudiantes analicen la realidad y actúen con una perspectiva histórica, aludiendo a un enfoque de carácter formativo y centrado en el análisis crítico de la información para la comprensión de hechos y procesos (SEP, 2007b: 37).

En la reforma impulsada por los gobiernos en turno, con clara continuidad sexenal, "los contenidos de Historia plantean superar el manejo eminentemente informativo de los temas con el desarrollo de competencias que articulan conocimientos, habilidades y actitudes que permiten a los estudiantes participar de manera responsable en situaciones de su vida personal y social". Se establecen las siguientes competencias: comprensión del tiempo y el espacio históricos; manejo de información histórica; formación de una conciencia histórica para la convivencia (DOF, 2006: 172).

Sin embargo, la enseñanza de la asignatura en este lapso de reforma dejó también preguntas de los propios profesores de Historia en la escuela secundaria:

¿cómo lograr que nuestros alumnos adolescentes en búsqueda y reafirmación de su identidad personal y social, insertados, al mismo tiempo, en un proceso de globalización, en que la personalidad es diluida por los instrumentos económicos que estandarizan al individuo, consideren interesante y trascendente el estudio de la Historia? (Juárez Casas, 2007: 20).

En el caso de los valores que se proponen desde los planteamientos oficiales, destaca el aspecto referido a la Consumación de la Independencia: identidad, libertad, ciuda- danía, democracia (DOF, 2006: 188). Sobre los aprendizajes esperados, se enfatiza el reconocimiento de la duración del periodo como una premisa inicial en todos ellos. En particular, se señala lo siguiente: "Ordenar cronológicamente en una línea del tiempo y establecer relaciones causales entre sucesos y procesos relacionados con el auge económico novohispano, la decadencia de la monarquía española y la Independencia de Nueva España" (DOF, 2006: 188). El tema de la Consumación de la Independencia (SEP, 2007b: 68) tiene una mención limitada y permite que los profesores incluyan sus propias posiciones e interpretaciones al respecto, haciendo énfasis en aspectos cronológicos y relaciones causales, que en términos formales no rebasarían las propuestas vigentes en periodos anteriores.

En el trasiego sexenal, aunque algunos términos cobraban nuevo sentido, mantenían una perspectiva que no daba viso alguno de discontinuidad o cambio. Podemos relacionar lo anterior al tránsito de administraciones de un mismo sello político, provenientes de un partido ubicado a la derecha dentro de la geografía política.

Así, a la Historia se le confiere la tarea de propiciar el análisis, la comprensión y el pensamiento claro y ordenado (SEP, 2011: 18). Para su enseñanza y valoración significativa, la propuesta recomienda actividades que permitan usar la imaginación y la creatividad (SEP, 2011: 18).

Respecto de los tiempos de la Historia, resalta la continuidad de lo universal a lo nacional, pero no en primer grado, sino en segundo. Asimismo, se tiene una reducción de la observancia de la materia, que en la anterior reforma provenía desde primer grado. Con estos contenidos a partir de segundo grado, se concluye un periodo de reforma que inició en la primera década de 2000 integrando la Educación Básica (SEP, 2011: 11).

El enfoque didáctico de la Historia es asumido como eminentemente formativo. "Hablar de una historia formativa implica evitar privilegiar la memorización de nombres y fechas, para dar prioridad a la comprensión temporal y espacial de sucesos y procesos" 
(SEP, 2011: 15). Con respecto a los contenidos, el programa de Historia I cubre cuatro siglos de historia del mundo que explica el proceso de integración de las diversas naciones. Historia II aborda las culturas prehispánicas al México actual (SEP, 2011: 20, 27).

En los contenidos de Historia I se percibe un bloque referente a la consumación de la independencia del país en el siglo XIX con resultado de los reacomodos políticos en Europa, en particular las guerras napoleónicas. En Historia II, el contenido referido a la consumación de la independencia se deriva del aprendizaje esperado: "Explica el proceso de Independencia y la influencia del liberalismo", esto como parte del tema "Hacia la independencia" (SEP, 2011: 42).

Para instituir una práctica docente acorde con tal reforma, la SEP propuso "generar ambientes de aprendizaje lúdicos y colaborativos que favorezcan el desarrollo de experiencias de aprendizaje significativas" (SEP, 2011: 56). En tal perspectiva, se afirmaba: "los ambientes de aprendizaje requieren brindar experiencias desafiantes, en donde los alumnos se sientan motivados por indagar, buscar sus propias respuestas, experimentar, aprender del error y construir sus conocimientos mediante el intercambio con sus pares" (SEP, 2011: 59), elemento fundamental del proceso de enseñanza que contrastaba con un sistema de evaluación que prefería el examen escrito para medir los aprendizajes. Entre las modalidades de trabajo sobresalieron los proyectos y las secuencias didácticas (2011: 60-61).

Hacia 2016, la SEP concluyó la segunda edición de las reformas emprendidas en tres sexenios gubernamentales donde hubo matices de alternancia política entre el PRI y el PAN. En el impasse de un periodo convulsionado por el movimiento social, sindical y político, se argumentaba plenamente a favor de una enseñanza que permitiera garantizar a los niños su derecho a una educación de calidad. En esa premisa se incluía también la enseñanza de la Historia, pues se trataba de propender un derecho de manera integral. Este esfuerzo había iniciado en 2012 y se proponía una duración de 12 ciclos para demostrar su maduración y concreción en las aulas (SEP, 2017: 19).

El ámbito en el que se inserta la Historia es el de Exploración y comprensión del mundo natural y social que, desde una mirada interdisciplinaria, pretendía lo siguiente:

Identifica una variedad de fenómenos del mundo natural y social, lee acerca de ellos, se informa en distintas fuentes, indaga aplicando principios del escepticismo informado, formula preguntas de complejidad creciente, realiza análisis y experimentos. Sistematiza sus hallazgos, construye respuestas a sus preguntas y emplea modelos para representar los fenómenos. Comprende la relevancia de las ciencias naturales y sociales (SEP, 2017: 158).

Los principios pedagógicos señalan la relevancia de un aprendizaje situado y la promoción de la interdisciplina. Sin embargo, en el caso de la Historia, el tiempo de clases se ve reducido en términos reales con 20 minutos menos que en periodos anteriores. Se señala un lapso de 4.4 horas a la semana en primer grado; 8.8 horas en segundo grado y 8.9 en tercer grado (SEP, 2017). Su integración conceptual disciplinaria deja dudas acerca de la naturaleza de su propia definición. De igual forma, aventura concepciones de la historia sin remitir a fuentes, referencias o fundamentos:

La historia estudia el cambio y la permanencia en las experiencias humanas a lo largo del tiempo en diferentes espacios. Su objeto de estudio es la transformación de la sociedad y la experiencia humana en el tiempo. Su propósito es comprender las causas y consecuencias de las acciones del ser humano por medio del análisis de los procesos económicos, políticos, sociales y culturales que se han gestado en el tiempo y en el espacio del devenir de la humanidad (SEP, 2017: 160).

Con respecto a los elementos de la anterior reforma, se continúa con un enfoque formativo, en el que los conocimientos históricos derivan de una construcción, consulta de fuentes primarias y procesos reflexivos 
dentro del proceso educativo (SEP, 2017: 162). En el entramado de los contenidos, resaltan elementos que poseen una pretensión de justificar el pasado. En el tema "El conocimiento histórico en un país colonizado", el aprendizaje esperado es: Analiza las razones por las que la historia de Occidente es también parte de nuestra historia (SEP, 2017: 175). Se trata de un intento de conciliación sobre posiciones que critican y han denunciado el sometimiento y la invasión que sufrieron los territorios y comunidades originarias en nuestro continente.

Con respecto a los temas y aprendizajes esperados, en tercer grado de secundaria se trabaja conceptualmente sobre Independencia, soberanía y nación. Se pretende llegar a un estudiante que: Analiza los principales proyectos e ideas independentistas que llevaron al surgimiento de una nueva nación. Reflexiona sobre la consolidación del dominio soberano del territorio nacional y cuáles fueron las principales amenazas (SEP, 2017: 189).

La principal consideración didáctica para el trabajo docente lo constituye la Unidad de Construcción del Aprendizaje, la cual propone una estructura, bajo el nombre de orientaciones didácticas para su desarrollo: Problema; Alcance, Organización, DesarroIlo, Productos, Presentación, Análisis y Evaluación (SEP, 2017: 218-219). Su aporte comprende un punto de análisis en relación con las producciones escolares presentadas por los estudiantes.

En estos primeros 20 años de reformas curriculares podemos encontrar algunos aspectos que, a la luz de las herramientas de análisis, nos permiten presentar resultados. La siguiente gráfica se deriva del plan de estudios de la reforma de sexenio 2001-2006 en el México del siglo XXI:

\section{Gráfica 1 \\ Historia 2006. Plan y programa de estudio de Secundaria}

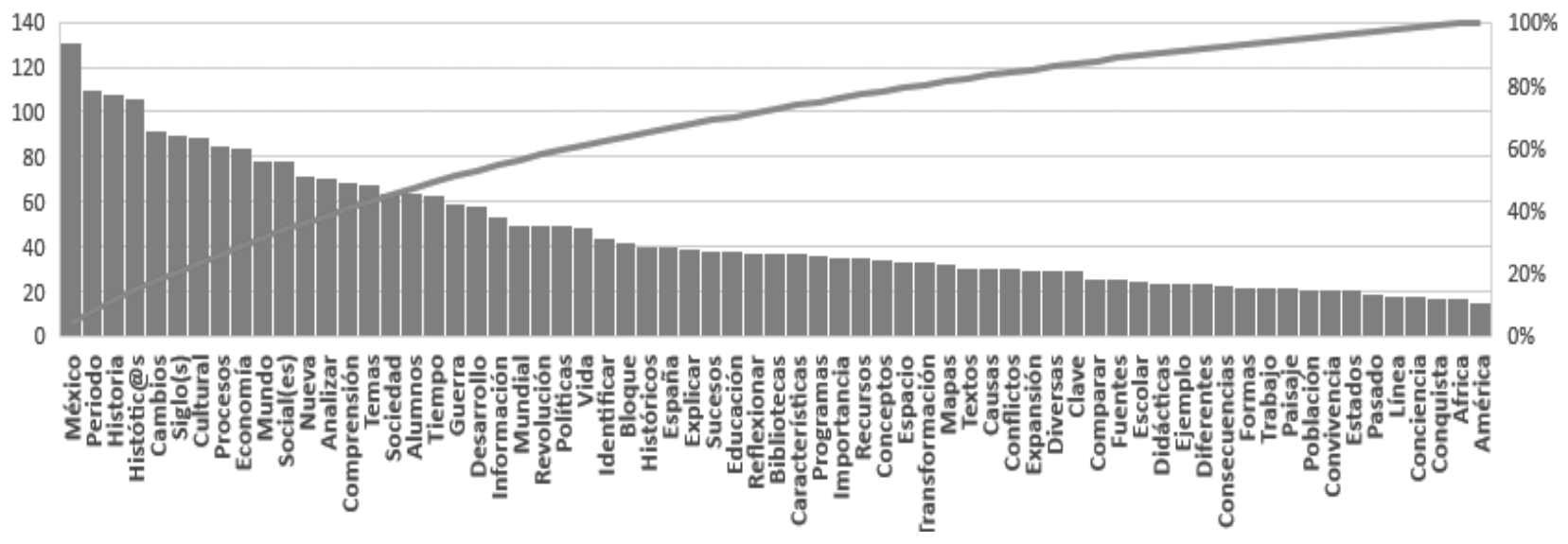

Fuente: elaboración propia. 
En una continua reforma, para 2011, en el marco de otro sexenio, se advertía el siguiente espectro conceptual en el programa de estudio:

\section{Gráfica 2 \\ Historia 2011. Plan y programa \\ de estudio de Secundaria}

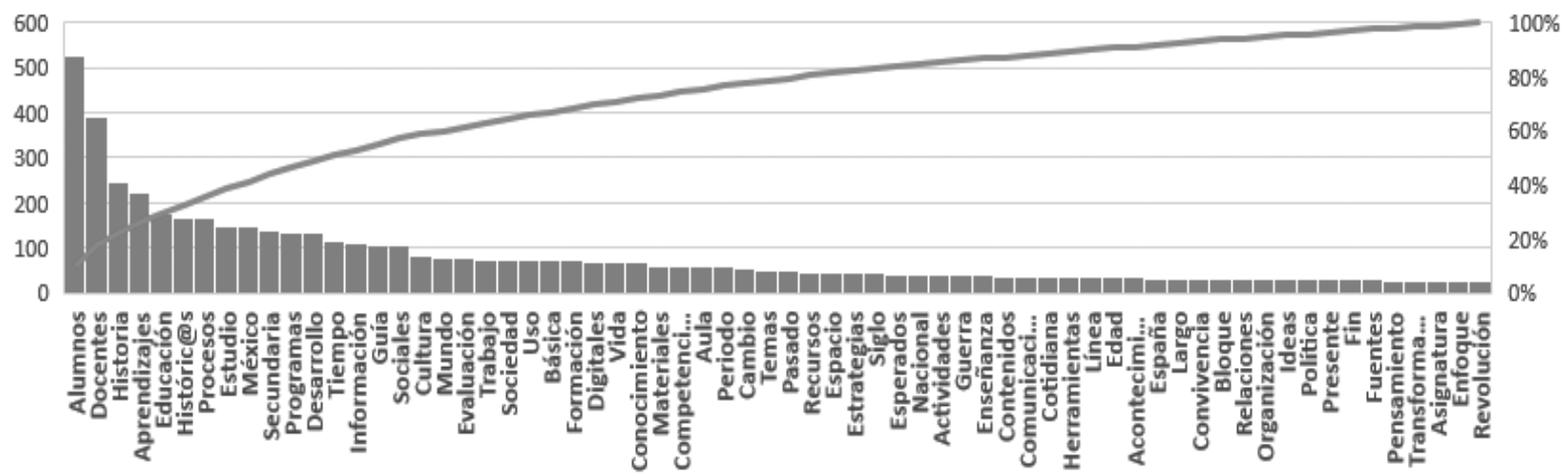

Fuente: elaboración propia.

Ya en el cierre de la segunda década, el panorama conceptual avizoraba los siguientes aspectos:

\section{Gráfica 3 \\ Historia 2017. Plan y programa \\ de estudio de Secundaria}

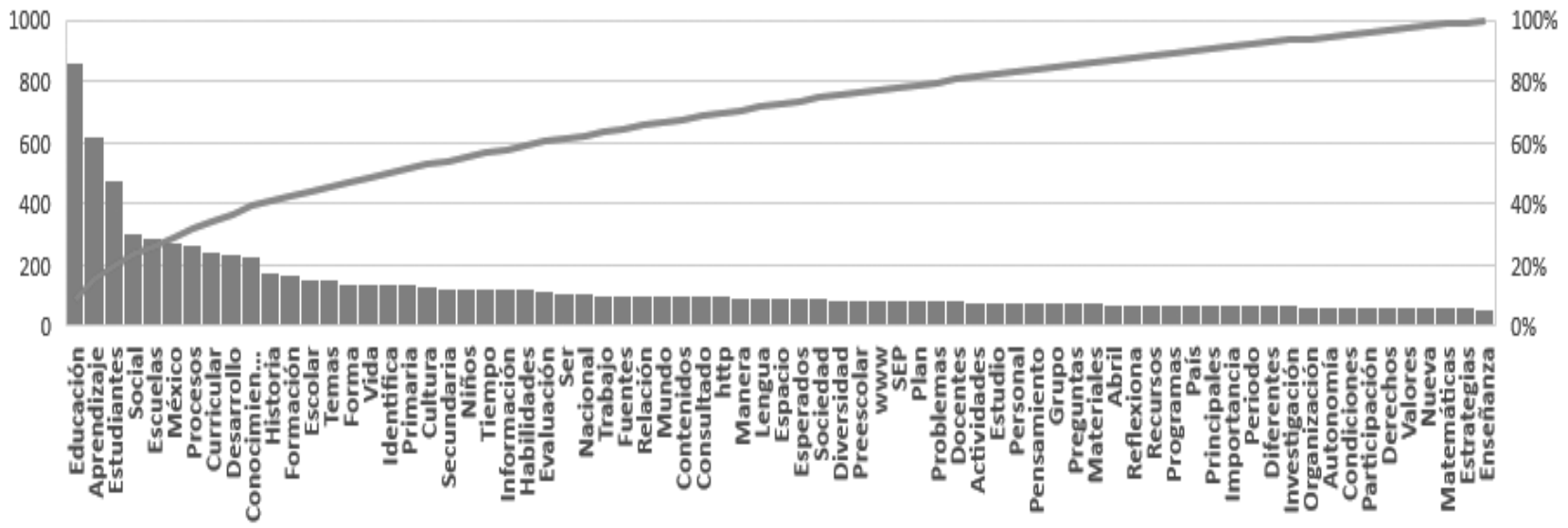

Fuente: elaboración propia.

Este análisis de contenido permite visibilizar aspectos conceptuales marcados por las coyunturas políticas. Se percibe el interés por centrar el discurso en los alcances pretendidos en el rubro de la Historia. En los dos primeros planes y programas (2006 y 2011), el interés apunta hacia el sentido histórico de un país en constante cambio; por su parte, en 
2017, la preocupación por la formación del estudiantado pone acento en aspectos centrales para la enseñanza de la materia.

En las gráficas de este artículo referentes a las producciones oficiales curriculares de los sexenios de 2000 a 2018, y específicamente en las fechas representativas 2006, 2011 y 2017, destaca el concepto de evaluación únicamente en las dos últimas. En 2006 no aparece dentro de la nube de palabras obtenida mediante Atlas.ti, pero en las discusiones posteriores cobra fuerza y se enquista en 2011 y 2017. En 2011, el concepto alcanza $1.4 \%$ de un corpus de contenido de entre 68 conceptos de primer orden, donde el término alumno alcanza 5.4\%. En 2017, de un total de 73 términos de mayor incidencia, el concepto evaluación alcanza 1.2\%, mientras que educación es el término más alto, con $8.9 \%$.

\section{Los cuadernos de historia de México de secundaria: análisis y resultados}

Para la investigación didáctica de la historia y las ciencias sociales los cuadernos escolares son una fuente histórica y socioeducativa que permite reconstruir, analizar y valorar las prácticas en la enseñanza de las disciplinas escolares; dilucidar las intenciones pedagógicas de la intervención docente $y$, sobre todo, reconstruir las prácticas de escritura y de lectura asociadas al uso de los libros de texto en el aula -los dos elementos centrales de la enseñanza y el aprendizaje de las disciplinas escolares-. El cuaderno escolar se considera fuente para el análisis e interpretación de la realidad diaria, tanto en el aula como de las prácticas que quedan registradas en estos artefactos culturales, en el modo de transmitir los contenidos y de organizar las actividades de acuerdo con los estilos docentes. Esta dimensión de análisis es lo que Anne-Marie Chartier denomina, metafóricamente, "la vitrina de la clase" (2005: 31). Dicha dimensión aporta nuevos elementos desde la perspectiva metodológica de la cultura escrita. Desde esta mirada, se considera al cuaderno de clase como un soporte físico, un espacio en el que queda registrada gran parte de la labor cotidiana realizada en el aula, pero también como un dispositivo escolar que conforma prácticas discursivas orales y escritas (2005: 34).

En esta investigación consideramos que el análisis de las producciones escolares es una fuente fundamental para "acercarnos a los tiempos" -ritmos, secuencias, momentos- reales de la actividad escolar y permite develar el discurso escolar: la tarea docente; la(s) cultura(s), los saberes, los contenidos y las disciplinas. Asimismo, abre la ventana al registro de rituales, inercias y permanencias en la historia enseñada a los adolescentes de las escuelas secundarias en un contexto curricular específico.

Los cuadernos escolares son huellas de la transposición real del currículo oficial a la práctica educativa (Cordova, 2016: 211). Los cuadernos son espacios de negociación de significados entre los materiales educativos, la mediación del profesor y los conocimientos previos e intereses de los alumnos. En este sentido, los cuadernos dan luz acerca de las adaptaciones, importancia e idea de qué actividad educativa (línea del tiempo, organizador gráfico, cuestionario, resumen, entre otros) es más importante para cierta información del libro de texto por parte de los profesores. Asimismo, el análisis de los cuadernos escolares permite comprender, como lo ha señalado Cordova (2016), las contribuciones de apropiación y resignificaciones de los contenidos curriculares que el alumno hace (2016: 211).

Lo anterior nos permite mirar diversas situaciones: el currículo oficial no se aplica de manera mecánica; las prácticas docentes no están totalmente apegadas a lo que indica el currículo oficial; existe una engorrosa normatividad, la cual se traduce en acuerdos administrativos que todos los profesores deben observar, y que intenta normalizar prácticas docentes en casi todos los aspectos escolares (la duración de cada materia -cinco horas para las más importantes, por ejemplo-, las actividades a realizar, las formas de evaluación, las opciones para los alumnos reprobados, entre otras cuestiones). 
Aunado a ello, este punto de vista saca a la luz la complejidad de la enseñanza de la historia en las aulas, con maestros y alumnos concretos, y empleando actividades variadas, unas emergentes y otras ya utilizadas desde hace muchos años. En estas prácticas pedagógico-educativas es posible distinguir la marca personal de cada profesor, desde la selección de la información que debe trabajar el grupo y las actividades de aprendizaje para aplicar a los alumnos, hasta los valores, actitudes y formas de trabajar que dejan huellas perdurables en los alumnos. Como lo han señalado Sanchidrián Blanco y Arias Gómez (2013), estos materiales permiten acreditar los contenidos y valores efectivamente enseñados en las escuelas, la forma de transmitirlos y su efecto en el aprendizaje de los niños, puesto que son el resultado de un proceso (2013: 258). Estas fuentes nos permiten ver las aportaciones de cada actividad de aprendizaje desarrollada para la formación escolar de los alumnos, pero también las debilidades en su concepción, elaboración y aplicación.

\section{Figura 1 \\ Portadas de los cuadernos de historia alusivas a la Independencia de México y su Consumación}

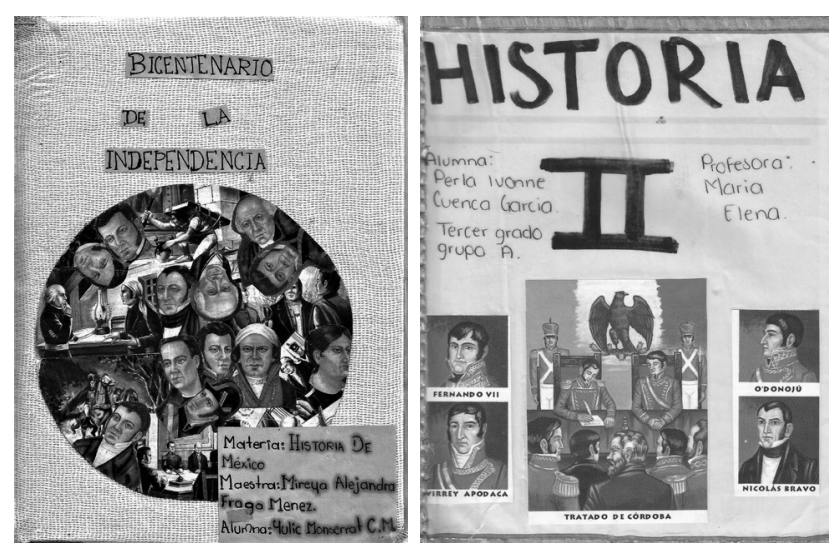

Fuente: Colección Digital de Cuadernos Escolares (CESHIS).

La mayor fortaleza de esta fuente para el análisis de los procesos de enseñanza y de aprendizaje de la asignatura de Historia de
México se encuentra en el tema de Consumación de la Independencia, impartido en tercer grado de educación secundaria. Sin embargo, no deben idealizarse las aportaciones de los cuadernos escolares. Estos conjugan una serie de problemas, como los siguientes: no siempre demuestran todo lo aprendido en un momento escolar determinado; no se conoce el libro de texto en que se basaron, pues cada profesor de secundaria puede seleccionar el libro que le parezca más adecuado; no es posible recuperar las interacciones que hay entre profesores y alumnos, y entre alumnos y alumnos.

\section{El método}

En un primer momento se realizó un análisis de contenido curricular a través del software Atlas.ti versión 20, donde se cargaron y analizaron los distintos planes y programas de estudio de Historia, diversos documentos normativos como acuerdos (2006), y planes y programas de las reformas educativas de 2006, 2011 y 2017, así como algunos estudios críticos de estos cambios. A través del análisis de Nube de palabras, se estableció la importancia de cada uno de los conceptos usados en función de la frecuencia de su aparición. De este modo se obtuvieron los datos que fueron presentados en el apartado 2.

En un segundo momento se aplicó un estudio de caso, entendido como el proceso de indagación sistemático y a profundidad de un fenómeno educativo -en esta situación, los cuadernos escolares como unidad-. El estudio de caso tiene un carácter explicativo porque pretende facilitar la interpretación de estrategias y procesos que intervienen en una acción educativa concreta: la enseñanza de la Historia de México (Bisquerra Alzina, 2016: 301-304).

Esta investigación se llevó a cabo gracias a la Colección Digital de Cuadernos Escolares de Historia (CESHIS), ${ }^{3}$ promovida por la

$\overline{3 \text { La CESHIS se }}$ creó en 2017 como parte de un proyecto de investigación interdisciplinario sobre cultura escrita y enseñanza de la historia en las escuelas primarias y secundarias del Estado de México. El acopio y sistematización de esta colección digital de cuadernos escolares es pionera en México. 
Universidad Pedagógica Nacional, Unidad 151-Toluca. La Colección se compone de 13 cuadernos escolares de diferentes secundarias (privadas, federales y estatales) del Valle de Toluca. La relación de cuadernos es la siguiente (Tabla 1):

\section{Tabla 1}

\section{Relación de cuadernos} de Historia de México

de tercero de secundaria, ciclo escolar y tipo de escuela

\begin{tabular}{|c|c|c|}
\hline Cantidad & Ciclo escolar & Tipo de secundaria \\
\hline 1 & $2010-2011$ & Secundaria Oficial \\
\hline 1 & $2011-2012$ & Secundaria Oficial \\
\hline 2 & $2015-2016$ & Secundaria Particular \\
\hline 4 & $2015-2016$ & Secundaria Técnica \\
\hline 9 & 2016-2017 & $\begin{array}{l}\text { (3) Secundaria Oficial } \\
\text { (5) Secundaria Federal } \\
\text { (1) Secundaria Federal } \\
\text { vespertino } \\
\text { (1) s/d }\end{array}$ \\
\hline
\end{tabular}

Fuente: Colección Digital de Cuadernos Escolares (CESHIS).

La indagación se llevó a cabo en 13 cuadernos cuyas fechas de elaboración se encuentran entre 2011 y 2016 . En todos ellos se ubicaron las actividades de enseñanza y aprendizaje implementadas por los respectivos profesores dentro del tema de Consumación de la Independencia; asimismo, se indagó en la manera en que los alumnos realizaron dichas actividades. A partir de esta ubicación, se analizó qué tan apegadas se encuentran a las actividades que teóricamente deben realizarse, así como las resignificaciones que los alumnos hacen de los materiales como el libro de texto, diccionarios y mapas comerciales, entre otros.

El primer nivel de análisis consistió en revisar y categorizar las actividades de enseñanza promovidas por los docentes y elaboradas por los alumnos en los respectivos cuadernos. Los resultados se presentan en la siguiente gráfica (Gráfica 4):
Gráfica 4

Actividades solicitadas por los profesores y desarrolladas por los alumnos en su cuaderno escolar. Asignatura: Historia de México.

Tercer año, nivel secundaria, tema "Consumación de la Independencia"

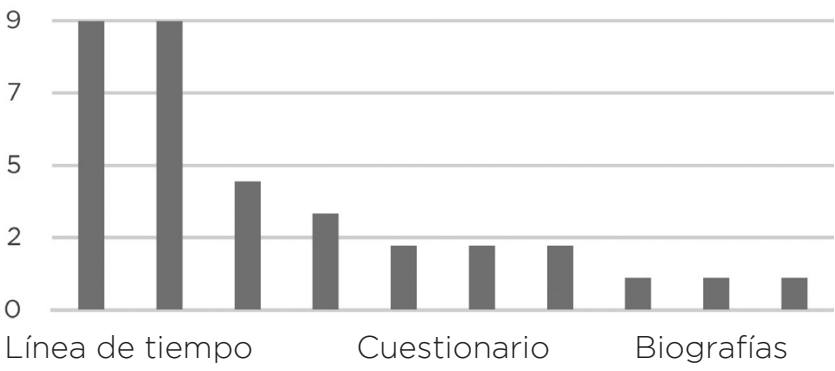

Fuente: elaboración propia.

Antes de iniciar el análisis particular de cada una de las categorías, es necesario señalar que las líneas del tiempo son las categorías más utilizadas. Éstas aparecen en los 13 cuadernos escolares, mientras que los resúmenes aparecen dos veces en los cuadernos de dos alumnos y en cuatro cuadernos no están presentes.

\section{Análisis de las producciones y actividades de los cuadernos escolares}

Enseguida, analizaremos las actividades desarrolladas por los alumnos.

Mediciones temporales: cronología, periodización y representación, a través de las líneas del tiempo

Las líneas del tiempo son representaciones gráficas usadas para simbolizar el transcurso del tiempo y marcar en ellas diversos hechos (políticos, sociales, de vida, científicos, tecnológicos, entre otros). Se emplearon por primera vez en los libros de Historia de primaria y secundaria elaborados en 1994 (SEP, 1994). Con ellas se pretende que los alumnos identifiquen las nociones para comprender el tiempo histórico, tales como cambios, continuidades, duración, sucesión, simultaneidad, etapas y periodos. Pueden 
ser temáticas e incorporar descubrimientos científicos, tecnológicos o hechos políticos.

Asimismo, pueden representar los sucesos diacrónicos (que duran el mismo o casi el mismo tiempo que el resto de los hechos en un cierto periodo; por ejemplo, el régimen virreinal terminó con la Independencia de México) y asincrónicos (los hechos históricos que traspasan la época histórica donde surgieron; por ejemplo, la religión católica o la hacienda rural, que surgieron durante el virreinato, pero sobrevivieron mucho después de la terminación de éste).

De las nueve líneas del tiempo, se distinguen cuatro modelos diferentes:

a) El modelo tradicional: una línea del tiempo horizontal con registros históricos abajo (GAPG).

\section{Figura 2}

\section{Línea del tiempo horizontal con registros históricos abajo}

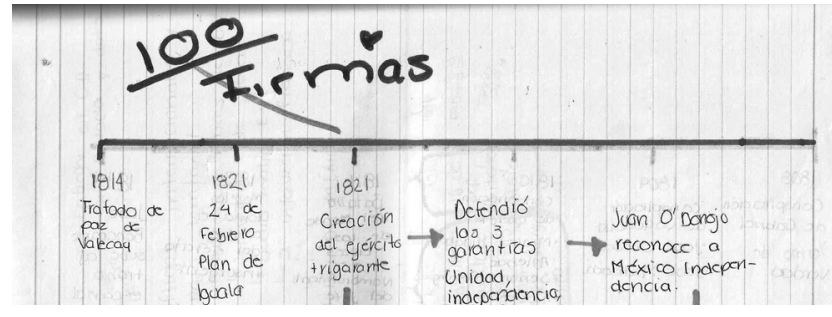

Fuente: Colección Digital de Cuadernos Escolares (CESHIS).

Esta línea de tiempo corresponde al modelo más simple encontrado en diversos libros de texto comerciales (en un libro de 1998 y también en otro de 2016). El alumno retomó parcialmente el modelo del libro, aunque construyó la línea sin tomar en cuenta que las divisiones de ésta deben tener la misma longitud: 2014 está muy cerca de 1821 y volvió a repetirlo adelante. Además, con las flechas el alumno intentó darle un sentido de causalidad: tras la creación del Ejército Trigarante que defendió las tres garantías, Juan O’Donojú reconoció la Independencia de México a través de los Tratados de Córdoba. La otra rama no es muy clara: según el ejercicio, la creación de dicho ejército ocasionó el Abrazo de Acatempan.
Aunque el ejercicio tiene errores -como repetir el año 1821 y el confuso sentido de causalidad con el Ejército Trigarante-, el docente no le hace observaciones de estos datos erróneos, sino que se concentra en anotar cuántas firmas ha reunido el alumno.

b) Una línea horizontal con información arriba y abajo (AP)

\section{Figura 3 \\ Línea del tiempo con registros históricos abajo y arriba}

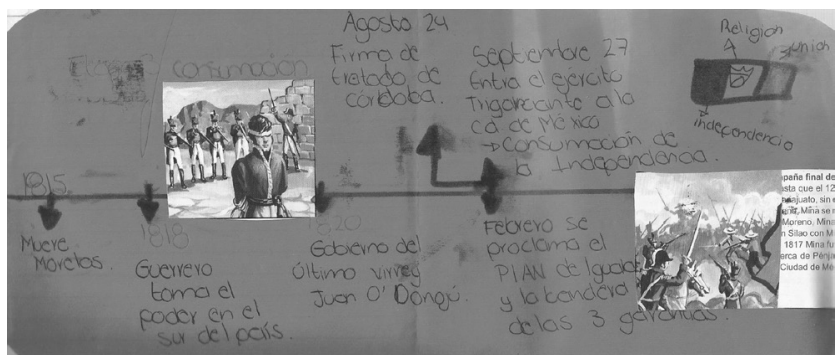

Fuente: Colección Digital de Cuadernos Escolares (CESHIS).

Esta línea del tiempo se desarrolla también de manera horizontal, pero tiene información abajo y arriba, como la mayoría de las líneas observadas en los libros de texto. Tal como la anterior, esta línea no está medida a precisión: la distancia de 1815 a 1818 es menor que la que hay entre 1818 y 1820 . En este último año, el alumno indica que transcurrió el gobierno del último virrey Juan O’Donojú; en febrero se proclamó el Plan de Iguala y la bandera de las tres garantías; en agosto se firmaron los Tratados de Córdoba; y en septiembre el Ejército Trigarante entró a la ciudad de México, lo cual ocasionó la consumación de la Independencia.

El alumno incluye tres imágenes: el fusilamiento de Vicente Guerrero (el cual ocurrió años después, y cuya imagen obliga al alumno a no marcar la distancia correcta entre 1818 y 1820), la imagen de una batalla de 1817 (donde aparecen Pedro Moreno y Javier Mina, según se aprecia en la foto) y un dibujo de la bandera trigarante. Al igual que la anterior línea, el profesor no marca los errores del alumno, sino que sólo palomea el trabajo. 
c) Una línea compuesta por dos tablas paralelas donde se consignan los hechos históricos sucedidos en México y en el mundo, respectivamente (DAC).

\section{Figura 4 \\ Línea del tiempo con dos tablas paralelas}

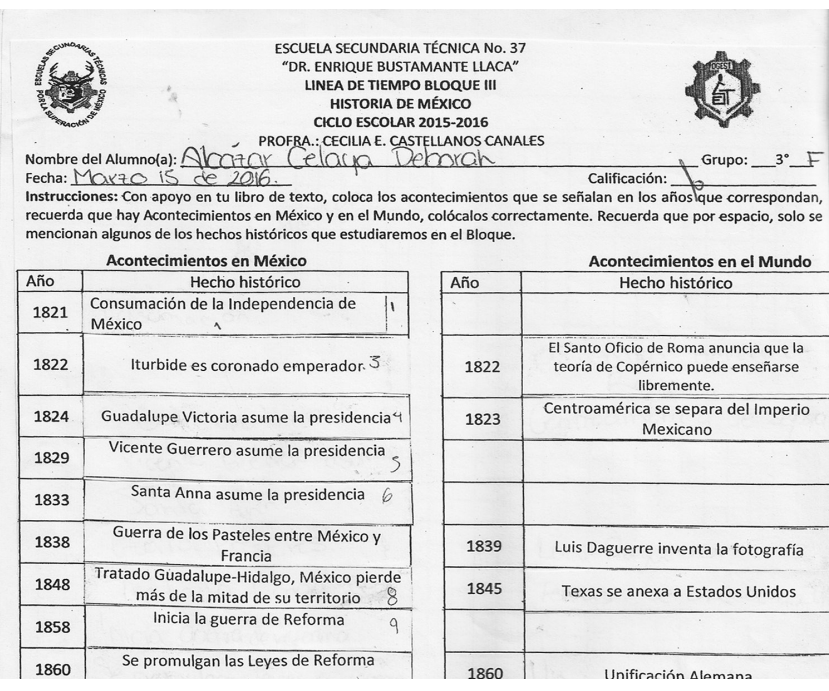

Fuente: Colección Digital de Cuadernos Escolares (CESHIS).

En esta línea del tiempo, a diferencia de las anteriores, se aprecia el diseño proporcionado por el profesor. Se pretende que los alumnos adquieran la noción de simultaneidad en los procesos históricos, mediante el contraste entre ambas columnas: la que contiene los eventos que sucedieron en nuestro país y la que recopila los que sucedieron en el mundo. En la primera columna, el alumno colocó hechos sucedidos en nuestro país, fundamentalmente políticos, mientras que en la del mundo incluyó algunos inventos.

Para cumplir con la tarea solicitada en el formato del profesor, el alumno no respeta la simultaneidad por entero, pues se ve obligado a intercalar años dispares en ambas columnas: 1824 (en México) corresponde a 1823 (en el mundo), 1838 (en México) corresponde a 1839 (invento de la fotografía). A causa del formato impuesto por el profesor, que el alumno sigue en afán de cubrir las expectativas docentes, se pierde la noción de simultaneidad: en un intento por hacer coincidir las fechas, el alumno altera el orden de los años en la segunda columna. Sin embargo, también es interesante notar que el alumno le imprimió su sello personal al ejercicio, pues en la segunda columna incluyó cuestiones de su interés: los inventos de la fotografía y el cinematógrafo, así como el primer viaje en autómovil.

Lo anterior demuestra claramente el interés del alumno por ciertos temas: la fotografía, el automóvil y el cinematógrafo en la columna del mundo, y la fundación de la Escuela Nacional Preparatoria, en la columna de México. Bien pudo seguir la lógica de los eventos políticos o militares, pero seleccionó hechos históricos de su propio interés. Esto demuestra cierta autonomía en la selección de los datos históricos para elaborar una línea de tiempo relativamente personalizada. Tal como sucede en las líneas anteriores, el profesor sólo estampó su firma en el punto de evaluación de su formato, sin hacer algún comentario al trabajo del alumno.

d) Línea del tiempo vertical

\section{Figura 5 Línea del tiempo vertical}

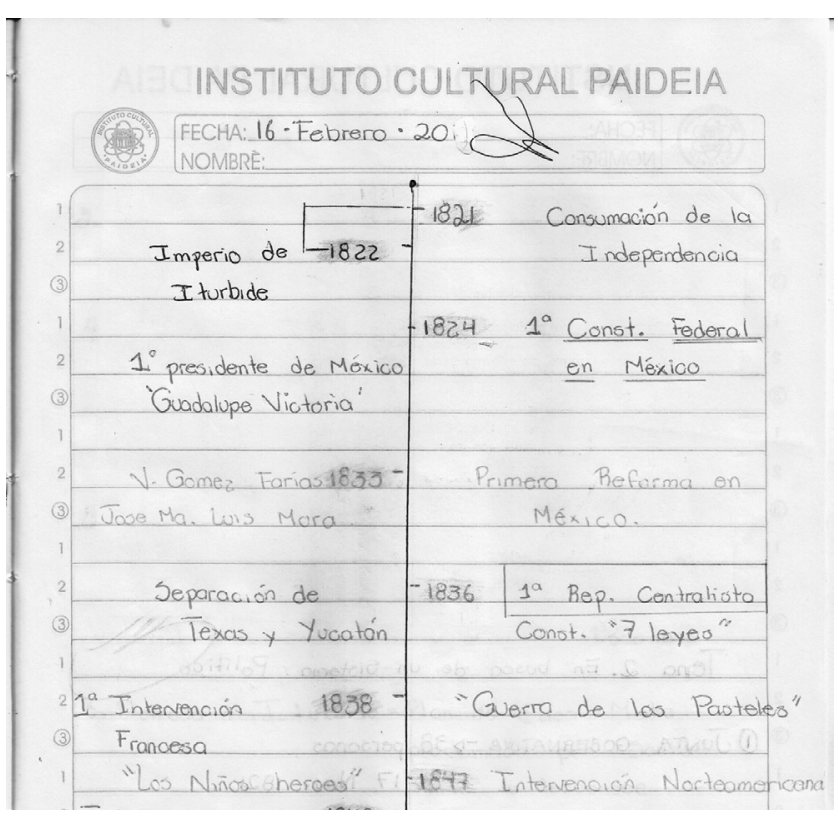

Fuente: Colección Digital de Cuadernos Escolares (CESHIS). 
El último modelo de línea de tiempo observada en los cuadernos es una línea vertical. Es un caso muy interesante porque las líneas más conocidas y difundidas son las horizontales, pues dan la idea de que el tiempo transcurre de acuerdo con el horizonte humano y no de arriba hacia abajo. Sin embargo, en la opinión de algunos autores, la verticalidad temporal puede ser un desarrollo específico de habilidades viso-espaciales: le facilita al alumno el aprendizaje del tiempo en términos de verticalidad más que de horizontalidad. En el ámbito universitario, en la enseñanza de la didáctica, varios alumnos las han realizado y afirman que aprenden más con líneas verticales que con las horizontales, aunque requieren más investigación.

Para este caso en particular, al inicio de la actividad el alumno tomó la mitad del renglón como medida del tiempo para cada año. Sin embargo, después traduce el espacio de ocho años transcurridos a lo que en su línea representarían tres años. Más adelante, en lo que representaría un solo año, incluye ocho (1838-1847). Así, el alumno modifica la medición del tiempo representada en la línea en función de la cantidad de información y del tamaño de hoja de papel que usó, por lo que se vio obligado a incluir en ella un periodo de 34 años. La posición vertical de la hoja del cuaderno limitó la extensión de la línea.

Es necesario señalar que este recurso es un producto exclusivo de la didáctica de la Historia, pues los historiadores profesionales no emplean líneas del tiempo en sus publicaciones y análisis. Se trata de un instrumento que nació fuera de la disciplina histórica. Asimismo, el instrumento requiere de la participación de historiadores, pedagogos, psicólogos, filósofos y otras disciplinas para analizar a profundidad los beneficios que ofrece, no sólo a la historia, sino a otras asignaturas en diversos ámbitos de aprendizaje.

Como se ha señalado en diversas investigaciones (Díaz Barriga et al., 2008: 144), la comprensión de la noción de tiempo histórico es compleja y difícil. Por poner algunos ejemplos derivados de investigaciones que los autores llevan a cabo: algunos niños de nivel primaria consideran que la batalla de Puebla del 5 de mayo ocurrió primero que el grito de Independencia que se celebra el 16 de septiembre; en licenciatura, algunos estudiantes no saben a qué corresponde el año 1135 y señalan que se trata del siglo I; en una línea cualquiera de tiempo los alumnos afirman que al año 0 estará siempre a la mitad de ella, aunque del lado de d.C. aumenten los años.

En el nivel de secundaria, los cuadernos muestran que los profesores dan por sentado que los alumnos han aprendido a elaborar líneas del tiempo en la primaria. Los profesores no dan instrucciones muy precisas de cómo construirlas, del periodo que abarcan (meses, años, décadas, entre otros periodos) $\mathrm{y}$, en función de esto, de cómo trazar la línea y hacer las divisiones de acuerdo con la escala seleccionada. Por esa razón los años marcados en las diferentes líneas tienden a ser arbitrarios.

Las líneas del tiempo son el recurso más utilizado en la enseñanza del Historia y, junto con los organizadores gráficos y el empleo de imágenes, han desplazado a los resúmenes y cuestionarios que predominaron desde 1960 hasta 1992-93. Éste es un rasgo positivo, pues implica el paso de una enseñanza escrita a una gráfica. Empero, los profesores siguen desaprovechando el potencial de este recurso para desarrollar nociones como cambio y continuidad, duración, sucesión, simultaneidad, periodización, así como la distinción entre procesos y hechos históricos.

En este sentido, desde la enseñanza, para ubicar los principales hechos políticos y militares en el periodo de la Consumación de la Independencia -tratados, constituciones, planes y la entrada del Ejército Trigaranteel libro incorpora la línea del tiempo, pues se trata de un lapso en donde se aceleró el tiempo histórico a causa de los conflictos sociales y políticos que acontecieron. Dichas contradicciones parecieran apremiar la historia, en el sentido en que aparentemente suceden más acontecimientos en compa- 
ración con los 300 años de virreinato, en los que la historia parece transcurrir más lentamente y donde no hay muchos sucesos para colocar en una línea del tiempo escolar. La línea c) muestra una innovación al incorporar la simultaneidad.

Para el aprendizaje, éstos son los elementos de información histórica reproducidos en las líneas por los alumnos. Sin embargo, como vemos en las líneas a) y c), los alumnos le otorgaron su propio significado al incorporar relaciones de causalidad y temas de interés propio, así como el sentido de orientación de horizontal a vertical, en la d).

En este sentido, el ejemplo a) alcanzaría dos niveles de los tres que componen la noción de tiempo histórico: el manejo de la cronología y la sucesión causal (Díaz Barriga et al., 2008: 143); mientras que la c) sólo el manejo de la cronología, y los otros dos ejemplos presentarían algunos problemas en este último aspecto.

\section{Representación del espacio y hechos} históricos en mapas e imágenes

En general, los libros de texto incorporan bastantes imágenes como mapas, litografías, maquetas, entre otros; de hecho, en los libros de texto hay muy pocas páginas sin imágenes y en el resto hay por lo menos una imagen. Estas imágenes cumplen, al menos, dos funciones pedagógicas: la ilustración de la información escrita y, en el caso de una historia explicativa, la comprobación. Sin embargo, no reflejan el hecho en sí, es decir, como evidencia única y contundente de un hecho, sino que se trata de una versión de tantas (Luna García, 2012: 147-148).

Uno de estos recursos es el mapa, el cual es una representación de diferentes espacios territoriales que permite a los alumnos ubicar en ellos localidades, estados, países y continentes (Gómez Gerardo, 2012: 170). Los autores agregarían que mientras que las líneas del tiempo permiten ubicar el tiempo histórico, los mapas son una de las herramientas esenciales para ubicar el espacio histórico. Enseguida se analizarán dos mapas presentados por alumnos. a) Mapa de la extensión de territorio del Virreinato, 1821

\section{Figura 6 \\ Mapa de la extensión de territorio del Virreinato, 1821}

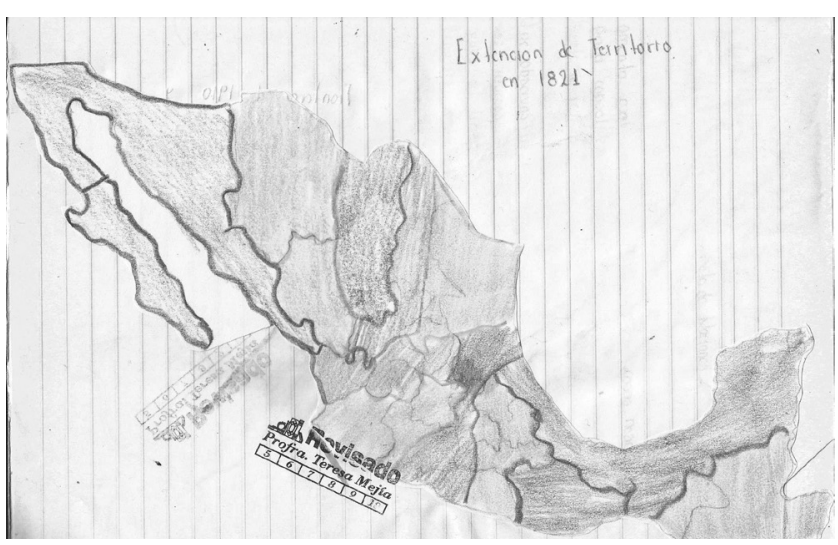

Fuente: Colección Digital de Cuadernos Escolares (CESHIS)

Según la anotación efectuada por el alumno, se trata del territorio novohispano en 1821. Sin embargo, es notorio que el mapa representa al territorio actual de México con una leve variación en la frontera sur. En la parte norte del país, el alumno reprodujo la división actual de México, con los estados de Baja California, Baja California Norte, Sonora, Chihuahua, Coahuila, Nuevo León y Tamaulipas y algunos estados más. En el centro no incorporó la división actual, mientras que en el sur juntó estados (Veracruz y Tabasco, Campeche y Yucatán).

Con este ejercicio, el alumno construye la noción de que el territorio actual de nuestro país se ha mantenido por mucho tiempo y ha sido reacio a las modificaciones. Como se aprecia, el alumno tampoco colocó otra indicación en el mapa. En este caso, como en otros anteriores, la profesora no hizo correcciones a esta actividad sino que únicamente estampó su sello y un tipo de paloma con color. 
b) Mapa del Virreinato

\section{Figura 7 Mapa del Virreinato}

INSTITUTO CULTURAL PAIDEIA

MÉxico durante el Imperio de Iturbide

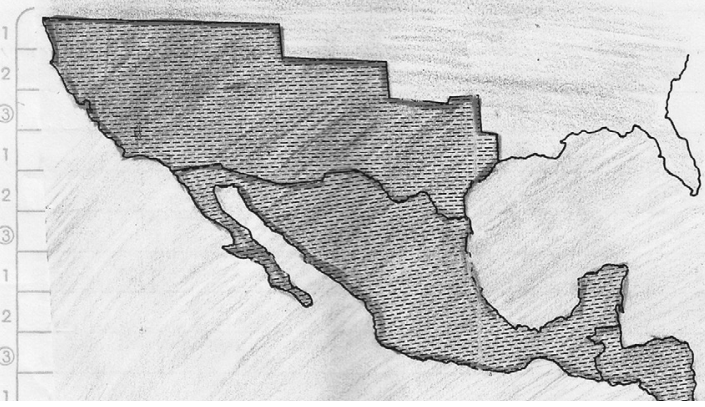

Fuente: Colección Digital de Cuadernos Escolares (CESHIS).

Este mapa representa con mayor propiedad el territorio novohispano durante el Imperio de Iturbide. Sin embargo, al igual que el anterior no tiene ninguna otra anotación o elemento histórico, como la división político-administrativa de ese tiempo.

Como hemos apuntado antes, se le ha asignado una función pedagógica a las representaciones gráficas, como la ilustración de información escrita que se localiza tanto en el libro de texto, o la que aparece en los cuadernos escolares. Otra función pedagógica es la de comprobación, pues según Carretero (citado en Luna, 2012: 148) cuando se presenta un tipo de historia explicativa, ésta tiene que estar basada en evidencias que puedan plasmarse en las representaciones visuales (como los mapas) para simbolizar mediante estas versiones los determinados contenidos que se presentan a los lectores (2005: 148). En estos casos particulares no hay alguna información histórica para ilustrar o comprobar la información escrita tanto en el libro como en el cuaderno escolar.

De esta forma, ha sido desaprovechado un poderoso recurso de aprendizaje porque los mapas, tal como las líneas del tiempo, pueden mostrar cambio y continuidades, transformaciones político-administrativas, exponer zonas productivas (mineras, agrícolas, comerciales, entre otras), núcleos de población, áreas donde se manifestaban conflictos o demandas sociales, políticas y económicas, o zonas de aparición de fuerzas insurgentes. Es decir, hay muchos elementos de análisis que podrían incorporarse en los mapas con el objetivo de crear un pensamiento histórico, y éstos no son retomados en los cuadernos analizados.

\section{La lógica del contenido en los organizadores gráficos y resúmenes}

\section{a) Organizadores gráficos}

Diversas lecturas incluyen en esta categoría a los mapas mentales, conceptuales, cuadros comparativos, mapas semánticos, redes semánticas, diagramas de flujo, mandalas. Se definen como recursos que abordan un contenido de visual con el uso, en algunos casos, de formas como líneas, círculos o cuadrados que se emplean para resaltar información, conceptos y relaciones entre ellos, así como diferentes jerarquías (Munayco Medina, 2018: s/p; Fuentes Monsalves, 2006: 148-149). Otros autores no se reducen a definirlos a partir de su contenido visual y los califican como estrategias didácticas para la construcción de conocimientos, pues señalan que facilitan la comprensión, organización y transformación de la información en conocimiento (Muñoz-González et al., 2011: 343).

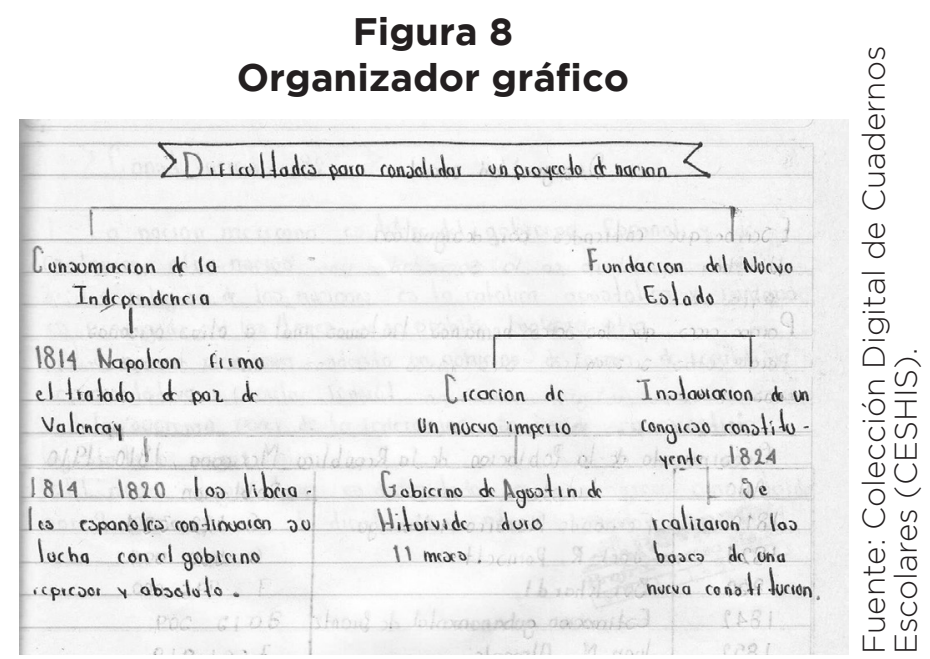


En la Figura 7 se presenta un organizador gráfico que aparece dos veces en cuadernos diferentes. No queda claro si es un mapa conceptual, pues se desarrolla hacia abajo y no hacia los costados como los mapas mentales, semánticos y redes. La información que coloca en los dos primeros niveles son subtítulos (Dificultades para consolidar un proyecto de Nación, Consumación de la Independencia y Fundacion (sic) del Nuevo Estado) tomados del libro de texto. En los niveles siguientes el alumno retoma los datos como si fuera una línea del tiempo, coloca los años 1814, 1820 y 1824, y enseguida narra sucintamente los sucesos subsecuentes, sin dar razones.

\section{Figura 9}

\section{Organizador gráfico: cuadro sinóptico y línea del tiempo}

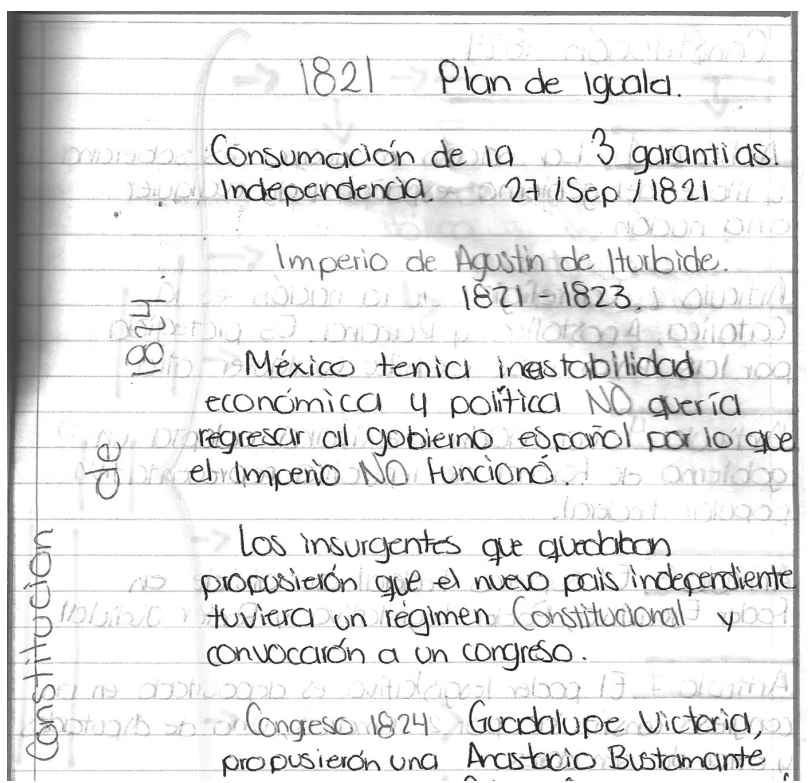

Fuente: Colección Digital de Cuadernos Escolares (CESHIS).

El siguiente organizador es un cuadro sinóptico que también es usado como línea del tiempo, pues incorpora las fechas y los hechos sucedidos respectivamente. Si bien todo esto lo engloba en la Constitución de 1824, se percibe un intento por vincular fechas, hechos y razones, y no únicamente colocar lo que ocurrió sin argumentar el porqué. Lo anterior puede apreciarse en las siguientes formulaciones: "México tenía inestabilidad económica y política NO (en rojo) quería regresar al gobierno español por lo que el imperio no funcionó", o "Los insurgentes que quedaban propusierón (sic) que el nuevo país independiente tuviera un régimen Constitucional (en rojo) convocarón (sic) a un congreso".

En los dos siguientes enunciados, el alumno mencionó cuáles fueron los personajes que propusieron una constitución y las nuevas características políticas que ésta estableció en el sistema político "Republicano, Federal y Popular". En estas líneas ya puede encontrarse un intento de construcción de conocimiento histórico, si bien es incipiente.

b) Resumen

Al igual que los esquemas, los resúmenes son considerados una técnica de aprendizaje. Se lo considera un escrito abreviado, somero y apegado a los aspectos más significativos de un texto (Beltrán Llera, 2003: 56). Se trata de actividades fácilmente visibles, operativas y manipulables. Aunque se piensa que esta técnica es una de las más empleadas en esta asignatura, lo cierto es que su uso ha disminuido sensiblemente, mientras que las representaciones visuales han aumentado su peso en la enseñanza de la Historia.

\section{Figura 10 Resumen}

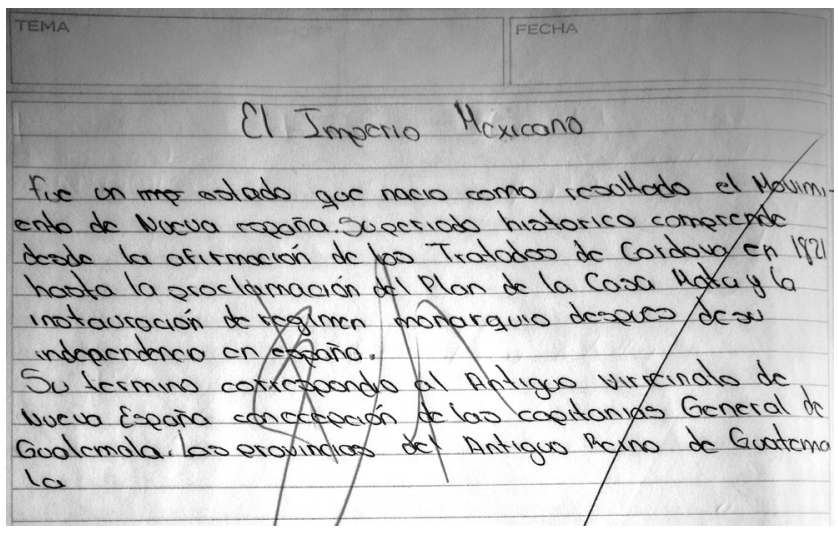

Fuente: Colección Digital de Cuadernos Escolares (CESHIS). 
Este resumen cumple con los requisitos: es breve, somero y seguramente se encuentra apegado al libro de texto empleado en ese grupo -se deduce por el tipo de lenguaje usado, pero es imposible de comprobar, pues no queda claro de qué libro de texto fue obtenido-. El alumno elaboró este resumen escribiendo relaciones causa-efecto: cómo nace un nuevo estado; la periodización del mismo (1821-1823) y su carácter monárquico, así como su extensión: el antiguo virreinato sin incluir las partes de Centroamérica.

Una tipología acerca de los tipos de escritos escolares establece tres niveles: descriptivo o declarativo, explicativo y argumentativo (Beltrán Llera, 2003: 57; Luna García, 2012: 148). El descriptivo ofrece detalles de las características de un fenómeno o acontecimiento; el explicativo da una visión objetiva sobre un hecho o fenómeno, $y$ el argumentativo ofrece recursos, pruebas, justificaciones y alegatos. Según esta tipología, el primer resumen sería un escrito descriptivo mientras que el segundo un explicativo, lo que implica un mayor grado de construcción del conocimiento histórico.

\section{c) Diccionario histórico}

La historia está llena de conceptos abstractos para los niños y jóvenes y hasta para muchos adultos. En la enseñanza de la historia en todos los niveles educativos, los diccionarios de conceptos históricos son imprescindibles para que los alumnos puedan entenderlos en un contexto determinado. A pesar de su importancia, de 13 cuadernos analizados sólo se encontró uno. Puesto que se trata del periodo de la Independencia y su Consumación, emergen los conceptos referentes a este periodo: Rebelión, Insurrección, Caudillo.

\section{Figura 11 Diccionario histórico}

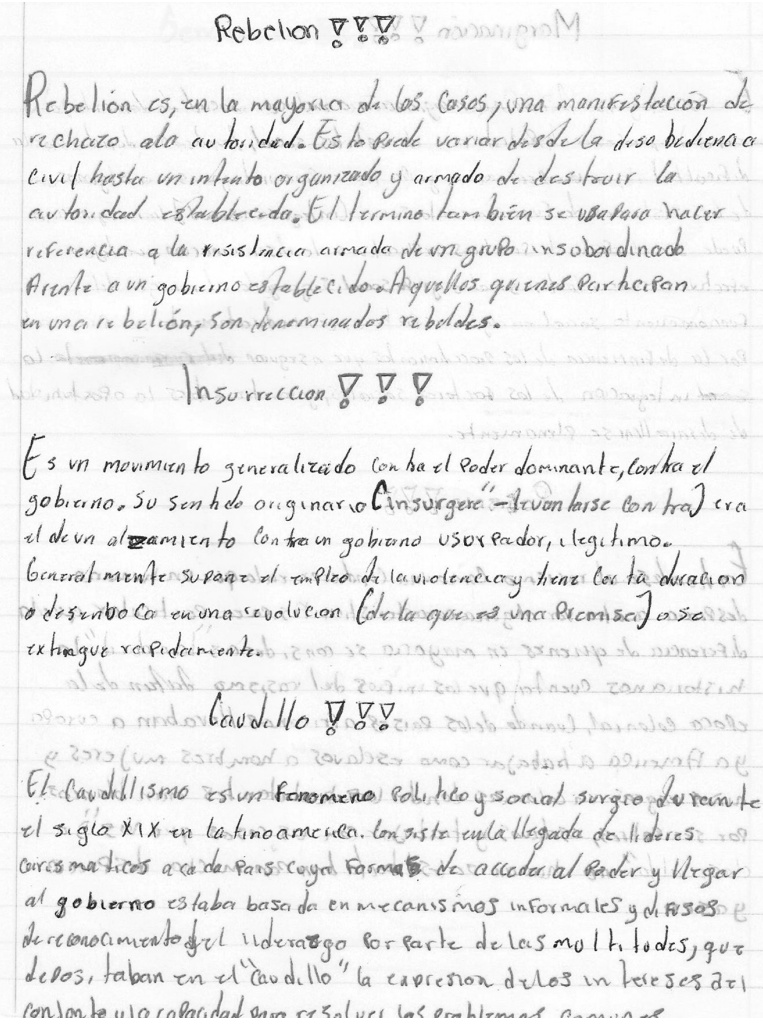

Rebelion es, en la mayoriar de los Casos, una manifestación de rechazo alo au toridado Es to pecele variar desodu la deso budiena a cive/ hasta un intanto or ganizardo y armado da des trour la

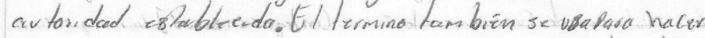
referencia a la vróstincea armade de un grupo in sobor dinado Arintz a un gobieino establecillo. A quatlos quienzs Parthcipan en una re belión, Son dicnaminados reboldes. lnsurreccion $\nabla ! \nabla$ Es un movimien to generalizado con ba el Poder dominante, contra d gobicrno. Su sen hedo originario Ainsurgere" - Irvon larse con traj eva il deun al amiento lon traun gobiano usoreador, ilegitimo. Generatimente su paño de impleo de la viotenciary tienz cor ta duradion

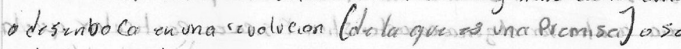
extiague rapidamiente.

Caudollo $\nabla \nabla \nabla$

El dav dillismo estun fonomeña Bobuhico y social surgre du veon te

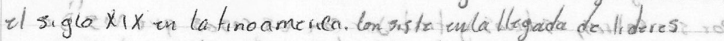

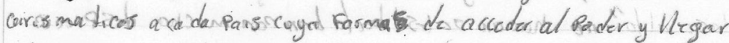
al gobierno es taba basa da en mecanis mos informales y difisos dereconocimentodul ilderazgo por parte de las mo 1 h. fodes, gue depos, taban en el "caudillo" la expresion dulos in tereses a 1

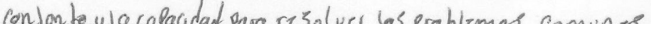

Fuente: Colección Digital de Cuadernos Escolares (CESHIS).

Esta actividad muestra que el profesor tuvo interés en que los alumnos entendieran los conceptos usados en el libro de texto del respectivo bloque. En general, en la práctica docente que predomina en las clases de historia, los docentes no ponen atención a la clarificación y entendimiento de los conceptos históricos sino que dan por hecho que son comprensibles para los niños y jóvenes, sin revisar si los conceptos escritos por el alumno son erróneos.

El beneficio que ofrece la introducción de un diccionario histórico se diluye cuando la información recabada responde a la acepción más moderna o aséptica del concepto o término. Por ejemplo, el término rebelión es tomado como un rechazo a la autoridad. Sin embargo, una rebelión también puede constituir un rechazo a un gobierno autoritario, dictatorial o impuesto desde el extranjero. Si se confía en la definición obte- 
nida de un diccionario escolar comercial, cualquier rebelión estará fuera de toda legalidad posible; sin que se introduzcan matices acerca del tipo de autoridad a la que aquella cuestiona.

Del término Insurrección, la primera acepción es igual que la anterior: un movimiento contra el gobierno, la autoridad, sin decir nada del carácter de ésta. En este caso, sin embargo, la segunda es el sentido que correspondería al periodo histórico analizado (Independencia y Consumación), porque los insurgentes lo consideraron un gobierno ilegítimo. A pesar de ello, el profesor no hizo énfasis en este último significado.

Finalmente, el término Caudillo -refiriéndose probablemente a Porfirio Díaz- es mostrado como alguien que gozaba del reconocimiento y liderazgo de parte de las multitudes. Según esta definición, por ello es por lo que, finalmente, ganó la presidencia y no como resultado de facciones político-militares, como sucedió con la lucha entre diferentes grupos liberales en la segunda mitad del siglo XIX. El uso de diccionarios escolares debería ser revisado cuidadosamente para evitar la aplicación de conceptos que no corresponden con un periodo histórico dado.

\section{El sentido de la evaluación del conocimiento}

Una parte de la vida escolar la constituye el aprendizaje obtenido en todo proceso educativo. En este sentido, hay muchas definiciones de qué es la evaluación del aprendizaje. Se retoma la siguiente definición: "La evaluación del aprendizaje conlleva a emitir un juicio fundamentado, basado en información apropiada y pertinente acerca de los aprendizajes desarrollados y logrados" (Medina-Díaz y Verdejo-Carrión, 2020: 273). La anterior definición implica compilar y concertar información cuantitativa y cualitativa, obtenida con instrumentos variados y en diferentes períodos. Enseguida veremos algunos de los criterios empleados por un profesor. ${ }^{4}$

4 Los criterios se encontraron solamente en dos cua-
En secundaria generalmente se le denomina escala evaluativa, pues establece varios elementos a valorar según los criterios de cada profesor. En el primer ejemplo el profesor establece cinco elementos: dos son procedimentales (cómo deben hacerse y presentarse los trabajos) y el resto se dirigen a evaluar los aprendizajes.

Figura 12 Formato de evaluación

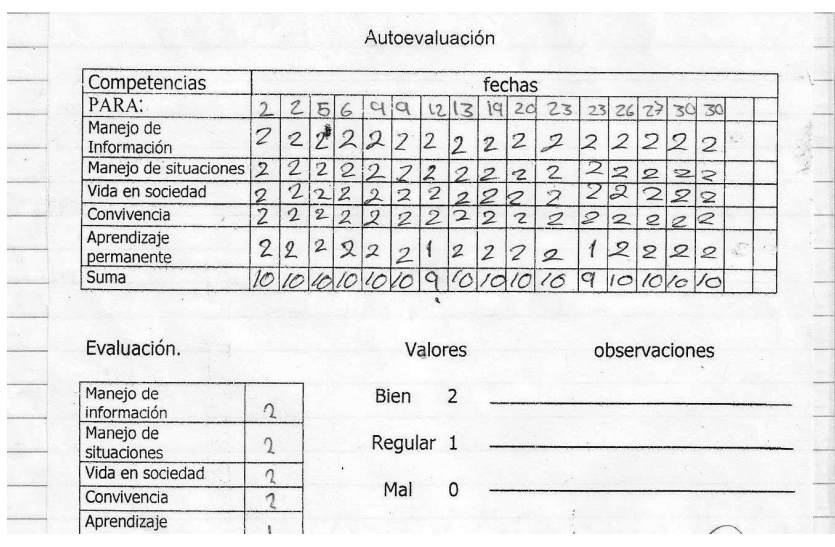

Fuente: Colección Digital de Cuadernos Escolares (CESHIS).

Esta escala evaluativa resalta las competencias que debe desarrollar el currículo de historia en secundaria establecidas por la SEP en 2007, y que son las siguientes:

1. Manejo de información y de situaciones donde se plantea la obtención y tratamiento de la información histórica y el aprendizaje de conceptos temporales (como cambio y continuidad, etcétera).

2. Las de vida en sociedad y convivencia que establecen que los alumnos actúen con conciencia histórica y presenten actitudes y valores para una convivencia democrática intercultural.

3. Con el aprendizaje permanente ubique procesos o sucesos en el tiempo, identifique múltiples relaciones, analice comportamientos humanos y explique situaciones de la escuela y la vida (Pagès, 2012: 29).

dernos; por razones de espacio en este artículo sólo se incorporó uno de los casos. 
En esta escala el profesor no determinó los criterios específicos de cada competencia con claridad, sino que los evaluó de forma general. Si los definió, estos no aparecen en el cuaderno escolar. En este caso, aplicó la autoevaluación, donde el alumno se puso 2 en todas las competencias, y la heteroevaluación, del profesor, quien también otorgó dos puntos para cada una de ellas. Al final, el alumno obtuvo 10 y un comentario de "has mejorado, muy bien". Puesto que los criterios no se encuentran precisados, la pregunta que surge es si el profesor ha calificado verdaderamente desde el enfoque de competencias.

\section{Discusión}

En esta investigación fue posible develar el significado del contenido histórico y pedagógico en la enseñanza de la Consumación de la Independencia en un corte temporal que incorpora dos momentos curriculares de la educación secundaria en México. El modelo didáctico para la enseñanza de la historia que implementa el profesor en el aula permite identificar la lógica del contenido y la organización de bloques y temas cuyos rasgos son visibles en los cuadernos escolares de sus estudiantes de secundaria (Rodríguez Frutos et al., 2017). El profesor determina dónde coloca el acento en el proceso de aprendizaje, pues selecciona para ello estrategias, habilidades y recursos específicos de mayor potencialidad que en el resto de las fases.

En los cuadernos de historia se identifican las palabras clave inscritas en los bloques, conceptos y contenidos globales, específicos y en las actividades de evaluación cualitativas y cuantitativas. La lógica de organización de los contenidos históricos se vislumbra en la red semántica del contenido de la Consumación de la Independencia, en dos momentos que marcan curricularmente la apertura del modelo por competencias y su continuidad en los aprendizajes clave.

\section{6-2011. Lógica del contenido Consumación de la Independencia y las habilidades del pensamiento histórico}

\section{Gráfica 5}

\section{Enseñanza de la Consumación de Independencia. Periodo 2006-2011}

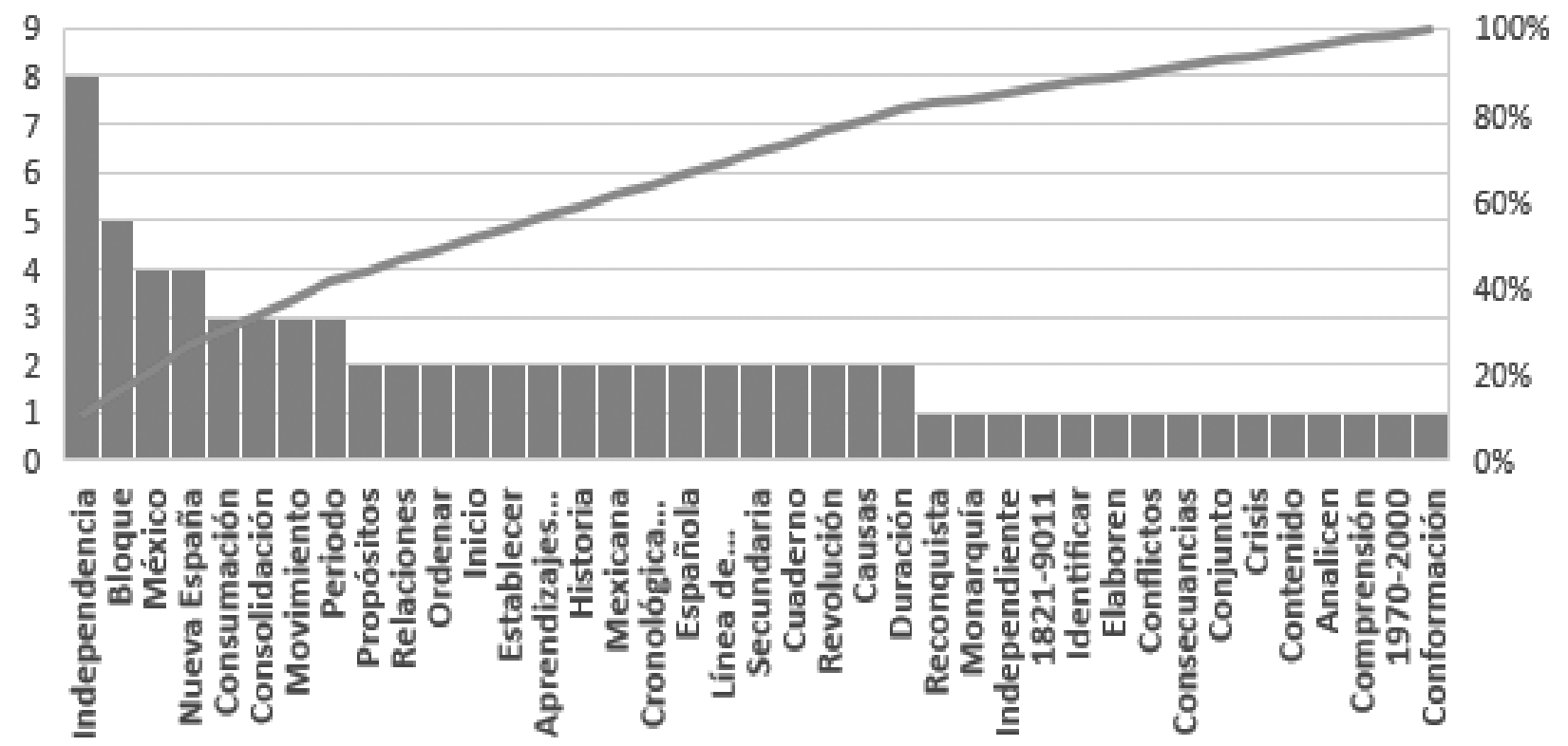

Fuente: elaboración propia. 
En la gráfica 5 se observa que el concepto de Independencia se asocia a un proceso histórico que inicia con la crisis de la monarquía, el movimiento insurgente y, finalmente, la Consumación la Independencia de México. En esta lógica es evidente el predominio de la historia política en los contenidos de la escuela secundaria, herencia de una fuerte tradición en la historia escolar de nuestro país. En el contenido histórico enseñado predominan conceptos de gran complejidad para los estudiantes, los cuales requieren, para su comprensión, del diseño de secuencias didácticas centradas en la lectura y decodificación de textos. Dichas actividades están definitivamente ausentes en los ejemplos aquí analizados.

La problemática que se desprende de los conceptos no se puede separar de los contenidos generales y específicos de enseñanza. El modelo instruccional se basa en una selección de contenidos específicos que resulten adecuados a las necesidades de los adolescentes, que generen la discusión y re- flexión y, sobre todo, que detonen nuevas preguntas en el alumno. De otra manera los conceptos históricos escolares se vuelven "irreconocibles al carecer de la vestimenta que cubra el cuerpo convirtiendo los conceptos en palabras desprovistas de significado" (Rodríguez Frutos et al., 2017: 73). En esta selección y tratamiento del contenido es evidente que la fragmentación de la información de los hechos y sucesos históricos de la consumación de la independencia son poco significativos para el lector alumno, pues no se relacionan con sus conocimientos previos o con preguntas que los interpelen desde el presente.

En la red semántica hay indicios de operaciones asociadas con el desarrollo de habilidades, como identificar y analizar periodos históricos. Sin embargo, la operación que tiene más peso es la de ordenar, que en los ejemplos se asocia únicamente con reproducir las fechas que señalan los libros de texto en los que predominan los contenidos de evaluación.

\section{2-2016. Lógica del contenido Consumación de la Independencia y las habilidades del pensamiento histórico}

\section{Gráfica 6 \\ Enseñanza de la Consumación de Independencia. Periodo 2012-2018}

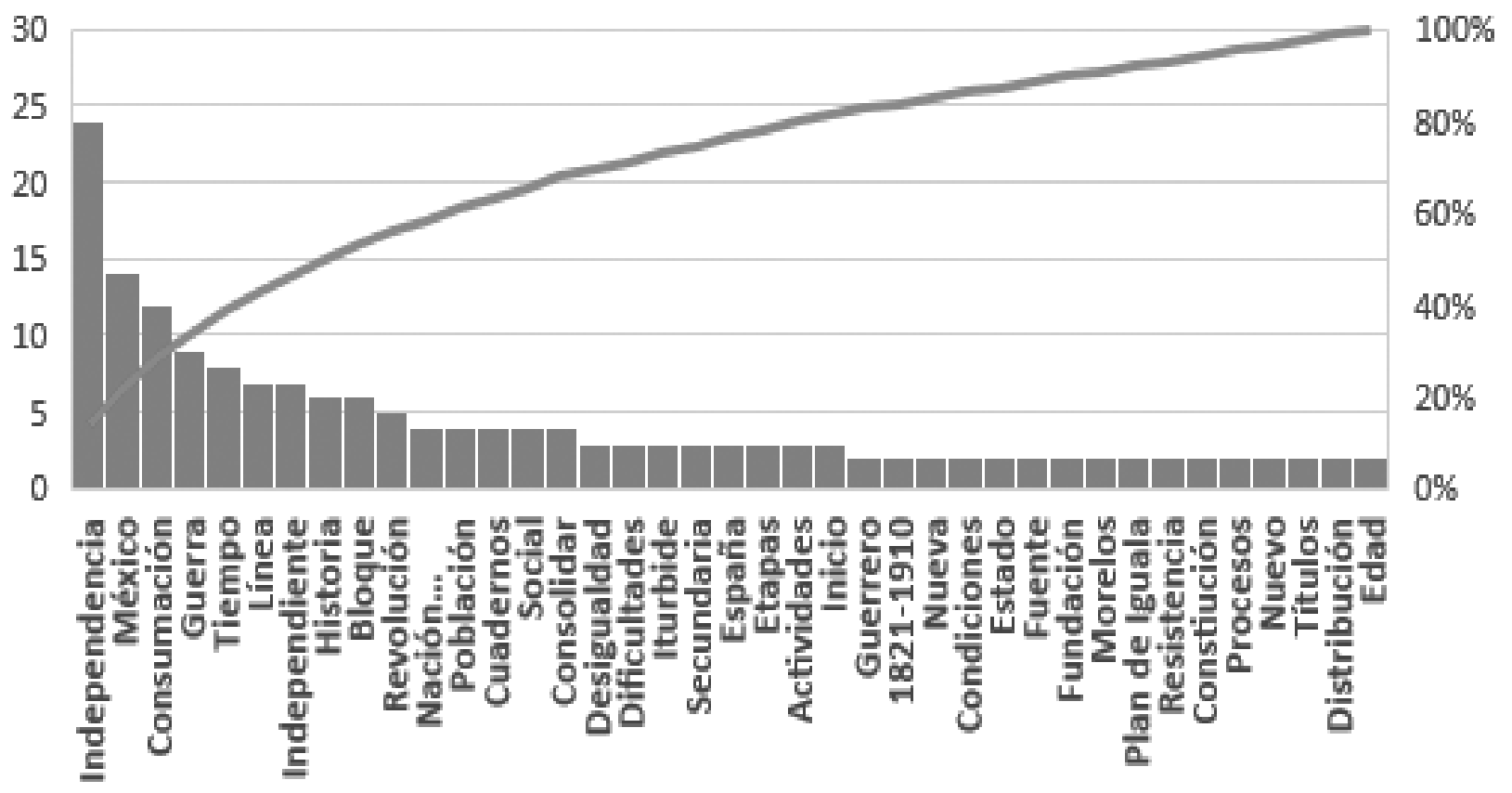


En esta red de palabras clave siguen apareciendo conceptos de primer orden que sitúan a los procesos en un tiempo y un contexto específico: etapas de la guerra de Independencia y su Consumación, las dificultades y desigualdades de la población en 1821, entre otros. Sin embargo, los ámbitos político, social, cultural y económico se siguen abordando de manera fragmentada y con ello se pierde su función explicativa.

Con la introducción del modelo por competencias en la educación básica se plantea también el uso y lectura de fuentes como una actividad para la enseñanza de la historia, en especial en secundaria. En esta gráfica existen indicios de incorporar las fuentes como un recurso en la enseñanza de la historia; sin embargo, el uso de fuentes primarias todavía es marginal y el predominio que sigue teniendo el libro de texto es evidente.

\section{Conclusiones}

La enseñanza de la historia de la consumación de la independencia en secundaria devela los siguientes rasgos: 1) El predominio que sigue teniendo la reproducción de contenidos de historia política cuyo tratamiento pedagógico desde los programas de estudio tiene escasa relación con la vida del adolescente de secundaria; 2) El tratamiento didáctico que requiere la ubicación temporal y espacial y el uso de conceptos históricos de la consumación de la independencia de México es de gran complejidad, pues exige o requiere de un andamiaje de actividades que despierten el interés y ayuden a la selección de fuentes que orienten nuevas preguntas desde el presente $\mathrm{y} / \mathrm{o}$ que cobren sentido para el alumno; y finalmente 3) La enorme presión sobre el ejercicio docente en secundaria propicia el predominio de prácticas instrumentales de la evaluación.

En contraste, los hallazgos muestran un importante esfuerzo del maestro por diversificar las actividades del alumno de secundaria para la enseñanza de la consumación de la independencia como acontecimiento histórico. Ejemplo de ello es el uso de or- ganizadores gráficos para la lectura de textos (en su mayoría textos escolares), cuyo potencial y desarrollo sistemático puede detonar en el adolescente una estrategia de lectura analítica y autónoma. El lenguaje gráfico es un elemento básico para el desarrollo del pensamiento histórico de las nuevas generaciones de cibernautas.

Desde un punto de vista pedagógico, es revelador el sentido de la evaluación del conocimiento histórico de las producciones escolares de secundaria del siglo XXI, tal como lo expresan las redes semánticas y actividades de los estudiantes de la escuela secundaria, cuyos cuadernos escolares pudieron rescatarse. Todo ello tiene un contraste con las posturas esgrimidas en planes y programas de estudio del periodo, y en las producciones que aquí se ha determinado analizar.

Es posible leer esta incidencia a la baja del papel de la evaluación como un reconocimiento de la crítica a los métodos evaluativos por no concordar pedagógicamente con los procesos didácticos, y más aún, pedagógicos, en el sentido de aplicarse principalmente a las producciones escolares. El mapa, la línea del tiempo, los resúmenes, los organizadores gráficos, los cuestionarios, las investigaciones y búsquedas reciben una valoración que acaba siendo evaluada y concretada en términos cuantitativos y numéricos, dejando fuera la personalidad y experiencia de cada alumno, cuyas condiciones de vida son diversas.

Dicho enfoque destaca a la evaluación en los planteamientos programáticos, y sus objetivos: esgrimir un sentido eficientista a los instrumentos y formas de evaluación autocalificadas como formativa, integrar los momentos de diagnóstica, formativa, sumativa u otros, que quedan fuera de la evaluación realizada en las aulas. Dichos momentos develan el predominio de un procedimiento instrumental expresado finalmente en una boleta de calificaciones, en la que "se rinde cuentas" del proceso educativo.

Lo analizado en los cuadernos escolares nos lleva a la necesidad de replantear la enseñanza de la historia y su función pe- 
dagógica, tomando en cuenta los contextos diversos de los alumnos, reorientar las actividades de aprendizaje que empleen nuevas fuentes históricas y que la evaluación realizada por los docentes retome el carácter formativo.

\section{Fuentes consultadas}

\section{Documentos de archivo}

Colección de Cuadernos Escolares de Historia (CESHIS)

\section{Referencias}

Beltrán Llera, Jesús (2003), "Estrategias de aprendizaje", Revista de Educación, núm. 332, Madrid, Universidad Complutense de Madrid, pp. 55-73, < https:// bit.ly/3jnZyuk>, 19 de abril de 2021.

Bisquerra Alzina, Rafael (coord.) (2016), Metodología de la investigación educativa, Madrid, La Muralla.

Chartier, Anne-Marie (2005), "Los cuadernos escolares: ordenar los saberes escribiéndolos", Conferencia presentada en el VIII Congreso Internacional de la cultura escrita, 5-8 de julio, Alcalá de Henares, Universidad de Alcalá.

Chevallard, Yves (1997), La transposición didáctica. Del Saber Sabio al Saber Enseñado, Madrid, Aique.

Cordova, Tania (2016), "Redações, cartas e composições livres: o caderno escolar como objeto da cultura material da escola", Revista História da Educação, 20 (49), Porto Alegre, Associação Sul-Rio-Grandense de Pesquisadores em História da Educação-Asphe/RS, pp. 209-226, <http:bit.ly/3tYQQqf>, 18 de abril de 2021.

Cuesta, Raymundo (1997), Sociogénesis de una disciplina escolar, Barcelona, Pomares.

Díaz-Barriga, Frida; García, Jesús-Antonio y Toral, Praga (2008), "La comprensión del tiempo histórico en estudiantes mexicanos de primaria y bachillerato", Cultura y Educación, 20 (2), Madrid, Fundación Infancia y Aprendizaje, pp. 143-160, <doi.org/10.1174/11356400878 4490352>, 16 de abril de 2021.

DOF (Diario Oficial de la Federación) (2006), "Acuerdo número 384 por el que se establece el nuevo Plan y Programas de Estudio para Educación Secundaria", 26 de mayo de 2006, Ciudad de México, Secretaría de Gobernación, <https://bit.ly/2TWL9MU>, 12 de abril de 2021.

Finocchio, Silvia (2021), "Nación: ¿Algo para recordar?, ¿algo para celebrar?, ¿algo para proyectar?", Sociales y escuela, <https://bit.ly/3yFlcAJ>, 15 de abril de 2021.

Finocchio, Silvia y Romero, Nancy (comp.) (2011), Saberes y Prácticas Escolares, Rosario, Homo Sapiens Ediciones.

Finocchio, Silvia (2005), "La ciudadanía en los cuadernos de clase", Enseñanza de las Ciencias Sociales, núm. 4, Barcelona, Facultad Latinoamericana de Ciencias Sociales, pp. 3-10. <https://bit. ly/3Ack7Ay>, 12 de abril de 2021.

Fuentes Monsalves, Liliana (2006), "Organizadores gráficos: un intento de valoración como estrategia de comprensión en estudiantes universitarios", Estudios sobre Educación, vol. 10, Pamplona, Universidad de Navarra, pp. 137-154, <http:bit.ly/3ezPD2c>, 17 de abril de 2021.

González, María Paula (2017), "La historia enseñada y sus transformaciones. Una aproximación desde las carpetas de estudiante", Pasado Abierto. Revista del CEHis núm. 6, Mar de la Plata, Universidad Nacional de Mar de la Plata, pp. 80-99, <http:bit.ly/3eBJtOZ>, 19 de abril de 2021.

González Iglesias, María Ximena (2017), "Las transformaciones en la historia enseñada: una mirada desde las carpetas de estudiantes de secundaria", ponencia presentada en las XVI Jornadas Inte- 
rescuelas/Departamentos de Historia, Mar del Plata, Universidad Nacional de Mar del Plata, en (coord.) Actas, Universidad Nacional de Mar del Plata, Mar del Plata, pp. 1-30, <http:bit.ly/3xsx7Bo>, 22 de abril de 2021.

Gómez Gerardo, Víctor (2012), "El uso de los mapas para la aprehensión de la noción de territorio en el siglo XIX", en Sebastián Pla, Xavier Rodríguez y Víctor Gómez (coords.), Miradas diversas a la enseñanza de la historia, Ciudad de México, Universidad Pedagógica Nacional, pp. 167-186.

Juárez Casas, Andrea Patricia (2007), "Enseñar para la vida a los alumnos adolescentes en el área de Historia", Entre maestr@s. Revista para los maestros de educación básica, 7 (22), Ciudad de México, Universidad Pedagógica Nacional, pp. 20-37, <https://bit.ly/3ruhXCP>, 31 de marzo de 2021.

Luna García, María Eugenia (2012), "Las mujeres comunes en el libro de historia de sexto de primaria. Para observadores", en Sebastián Pla, Xavier Rodríguez Ledesma y Víctor Gómez Gerardo (coords.), Miradas diversas a la enseñanza de la historia, Ciudad de México, Universidad Pedagógica Nacional, pp. 139-168.

Medina-Díaz, María y Verdejo-Carrión, Ada (2020), "Validez y confiabilidad en la evaluación del aprendizaje mediante las metodologías activas", Alteridad. Revista de Educación, 15 (2), Quito, Universidad Politécnica Salesiana, pp. 270-288, <http:bit.ly/3gJSwQK>, 20 de abril de 2021.

Mirnada, Francisco y Reynoso, Rebeca (2006), "La Reforma de la Educación Secundaria en México. Elementos para el debate", Revista Mexicana de Investigación Educativa, 11 (31), Ciudad de México, Consejo Mexicano de Investigación Educativa, A.C., pp. 1427-1450, <https://bit.ly/3xs58R2>, 15 de abril de 2021.
Monterrosas Gil, Gustavo (2000), "La narrativa como recurso en la enseñanza de la historia de México", Cero en conducta, 14 (48), pp. 71-78.

Munayco Medina, Alfredo (2018), "Influencia de los organizadores gráficos en la comprensión lectora de textos expositivos y argumentativos", comunic@ ción, 9 (1), Lima, Institución Educativa Emblemática Juan Guerrero Quimper, <http:bit.ly/ 3vmu1x2>, 21 de abril de 2021.

Muñoz-González, Juan Manuel; Ontoria-Peña, Antonio y Molina-Rubio, Ana (2011), "El mapa mental, un organizador gráfico como estrategia didáctica para la construcción del conocimiento", Magis. Revista Internacional de Investigación en Educación, 31 (6), Bogotá, pp. 343361, <http:bit.ly/3tXtS2Y>, 21 de abril de 2021.

Pagès, Joan (2012), "Las competencias ciudadanas, una finalidad de la enseñanza de la historia", en Sebastián Pla, Xavier Rodríguez Ledesma y Víctor Gómez Gerardo (coords.), Miradas diversas a la enseñanza de la historia, Ciudad de México, Universidad Pedagógica Nacional, pp. 19-66.

Quiroz, Rafael (1999), "Reforma de la educación secundaria en México: currículum y prácticas de enseñanza", Cero en conducta, núm. 47, pp. 95-113.

Rodríguez Frutos, Julio; Campuzano Ruiz, Antonio; Valdeón Baruque, Julio; De las Heras, Antonio R.; Aróstegui Sánchez, Julio y Pagés Blanch, Joan (2005), Enseñar Historia. Nuevas propuestas, Ciudad de México, Fontamara.

Salazar, Julia (2018), ¿Por qué enseñar historia a los jóvenes? Una reflexión sobre el sentido de la historia en la formación de las identidades en el México globalizado, Ciudad de México, Universidad Pedagógica Nacional.

Salazar Sotelo, Julia (2012), "Una mirada a la cultura histórica en la sociedad mexicana", en Sebastián Pla, Xavier Rodrí- 
guez Ledesma y Víctor Gómez Gerardo (coords.), Miradas diversas a la enseñanza de la historia, Ciudad de México, Universidad Pedagógica Nacional, pp. 91-114.

Salazar Sotelo, Julia (2011), "Cambios en los valores de la identidad nacional en estudiantes de tercer año de secundaria de la ciudad de México", Ponencia presentada en el XI Congreso Nacional de Investigación Educativa, Memoria electrónica, <https://bit.ly/3yFr4tL>, 14 de mayo de 2021.

Sánchez Quintanar, Andrea (2002), Reencuentro con la Historia. Teoría y praxis de su enseñanza en México, Ciudad de México, UNAM-Facultad de Filosofía y Letras/Paideia.

Sanchidrián Blanco, Carmen y Arias Gómez, Bárbara (2013), "La construcción de la identidad nacional española a través de los cuadernos escolares (1957-1959)", Revista de Investigación Educativa, 31 (1), Murcia, Universidad de Murcia, pp. 257-274, <http:bit.ly/3xuzbJm>, 18 de abril de 2020 .

SEP (Secretaría de Educación Pública) (2017), "Historia educación secundaria. Plan y programas de estudio, orientaciones didácticas y sugerencias de evaluación. Aprendizajes clave para la educación integral", Ciudad de México, SEP

SEP (Secretaría de Educación Pública) (2011), "Programas de estudio 2011. Guía para el maestro. Educación Básica Secundaria Historia", Ciudad de México, SEP.

SEP (Secretaría de Educación Pública) (2007a), "Educación Básica. Secundaria, Plan de Estudios 2006", Ciudad de México, SEP.

SEP (Secretaría de Educación Pública) (2007b), "Historia. Programas de estudio 2006", Ciudad de México, SEP.

SEP (Secretaría de Educación Pública) (2002), "Documento base. Reforma Integral de la Educación Secundaria de la Subsecretaría de Educación Básica y Normal", Ciudad de México, SEP.

SEP (Secretaría de Educación Pública) (1994), Historia. Cuarto Grado, Ciudad de México, Conaliteg, <http:bit.ly/ 3vlySyD>, 16 de abril de 2020.

Villalón-Gálvez, Gabriel, Cavieres-Fernández Eduardo, Vásquez Leyton, Gabriela (2020), "Vinculando la enseñanza de la independencia nacional con temas socialmente relevantes para la transformación de ciudadanos", Revista Sophia Austral, núm. 26, Chile, Universidad de Magallanes, pp. 33-50, <https://bit. ly/3ioMYeL>, 29 de abril de 2021.

Recibido: 17 de mayo de 2021. Reenviado: 18 de mayo de 2021. Aceptado: 25 de junio de 2021. 


\section{María Guadalupe Mendoza Ramírez}

Es doctora en Ciencias Sociales por El Colegio Mexiquense, A.C. Sus líneas de investigación son Enseñanza de la Historia y Libros de texto y cultura escrita. Entre sus más recientes publicaciones destacan, como coautora: "La colección digital de cuadernos de historia en la educación básica: una fuente documental para la investigación de las prácticas escolares en México", Revista RedCA, 3 (8), Toluca, Universidad Autónoma del Estado de México, pp. 79-101 (2020) y "Las prácticas de enseñanza desde el aula: un acercamiento a los cuadernos de historia de México de primaria y secundaria de la RIEB", Correo del maestro, núm. 280, Ciudad de México, pp. 29-38. (2019); como autora: Los libros de texto de Historia y la función del maestro en la secundaria socialista y de Unidad Nacional (1934-1959), Ciudad de México, Universidad Pedagógica Nacional, 37 pp. (2021).

\section{Rodolfo Huerta González}

Es maestro en Historia por la Universidad Autónoma Metropolitana-Unidad Iztapalapa. Sus líneas de investigación son Enseñanza de la Historia, Cuadernos Escolares y Mapas conceptuales. Entre sus más recientes publicaciones destacan, como coautor: "La colección digital de cuadernos de historia en la educación básica: una fuente documental para la investigación de las prácticas escolares en México", Revista RedCA, 3 (8), Toluca, Universidad Autónoma del Estado de México, pp. 79-101 (2020) y "La interdisciplina en las tesis de la Especialización y Maestría en Enseñanza de las Humanidades: un camino por recorrer", en Julieta Flores Michel, Irma Leticia Garza González y Ana Irene Cuevas Gutiérrez (eds.), Inclusión educativa, estrategias y resultados Tendencias y procesos educativos, Universidad Autónoma de Nuevo León, pp. 43-49 (2020).

\section{Rodolfo Cruz Bustos}

Es doctor en Educación por el Instituto Superior de Ciencias de la Educación del Estado de México. Sus líneas de investigación son Prácticas pedagógicas y procesos educativos y Políticas de innovación en la formación de docentes desde una perspectiva comparada. Entre sus más recientes publicaciones destacan, como autor: "Innovación, Formación Docente y Políticas Educativas en México. Hacia una Reconstrucción desde el Sujeto", Tiempo de Educar, 9 (17), Toluca, Universidad Autónoma del Estado de México, pp. 83-118, (2008) y "El sujeto docente: una mirada en el contexto político educativo", Revista Universitaria núm. 7 , Ciudad de México, Universidad Pedagógica Nacional, pp. 1-12 (2011). 


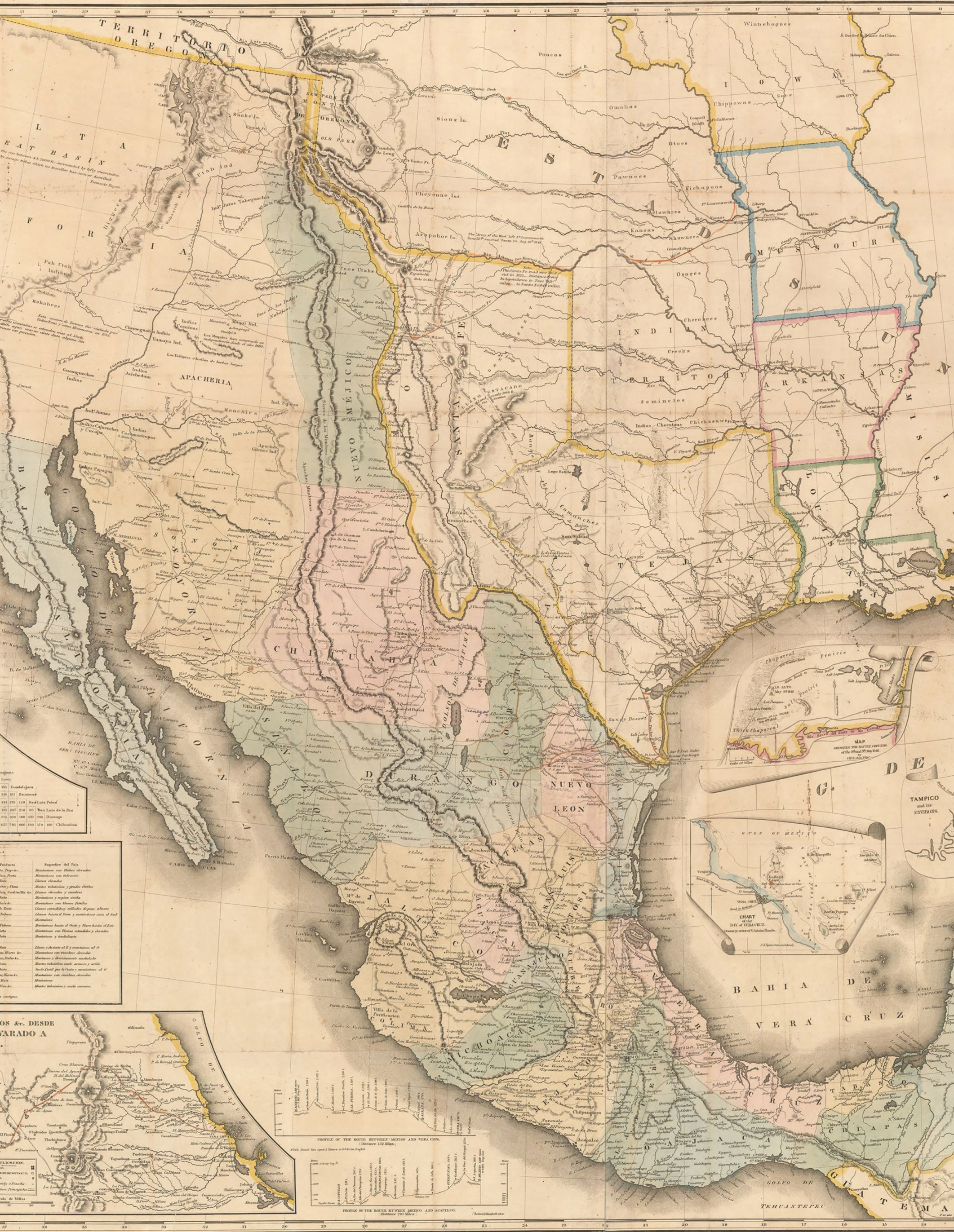

